\title{
Invited review: Sphingolipid biology in the dairy cow: The emerging role of ceramide
}

\author{
J. W. McFadden* and J. E. Rico \\ Department of Animal Science, Cornell University, Ithaca, NY 14853
}

\section{ABSTRACT}

The physiological control of lactation through coordinated adaptations is of fundamental importance for mammalian neonatal life. The putative actions of reduced insulin sensitivity and responsiveness and enhanced adipose tissue lipolysis spare glucose for the mammary synthesis of milk. However, severe insulin antagonism and body fat mobilization may jeopardize hepatic health and lactation in dairy cattle. Interestingly, lipolysis- and dietary-derived fatty acids may impair insulin sensitivity in cows. The mechanisms are undefined yet have major implications for the development of postpartum fatty liver disease. In nonruminants, the sphingolipid ceramide is a potent mediator of saturated fat-induced insulin resistance that defines in part the mechanisms of type 2 diabetes mellitus and nonalcoholic fatty liver disease. In ruminants including the lactating dairy cow, the functions of ceramide had remained virtually undescribed. Through a series of hypothesis-centered studies, ceramide has emerged as a potential antagonist of insulin-stimulated glucose utilization by adipose and skeletal muscle tissues in dairy cattle. Importantly, bovine data suggest that the ability of ceramide to inhibit insulin action likely depends on the lipolysis-dependent hepatic synthesis and secretion of ceramide during early lactation. Although these mechanisms appear to fade as lactation advances beyond peak milk production, early evidence suggests that palmitic acid feeding is a means to augment ceramide supply. Herein, we review a body of work that focuses on sphingolipid biology and the role of ceramide in the dairy cow within the framework of hepatic and fatty acid metabolism, insulin function, and lactation. The potential involvement of ceramide within the endocrine control of lactation is also considered. Key words: ceramide, insulin, lactation, liver

Received December 3, 2018.

Accepted April 30, 2019.

*Corresponding author: McFadden@cornell.edu

\section{INTRODUCTION}

The discovery of sphingolipids is attributed to the work of Johannes Ludwig Thudichum, who characterized the chemical composition of brain (Thudichum, 1884). The structure of sphingolipids was described by the existence of an 18-carbon sphingoid base backbone called "sphingosin" and "the many enigmas which it presented to the inquirer." Indeed, sphingolipids are often described by their amphipathic nature, which explains their "sphinx-like" properties that dictate their bioactive and structural functionality. Major sphingolipid subclasses include dihydroceramides, ceramides (nonglycosylated or glycosylated), sphingomyelins, and gangliosides. The complexity of the sphingolipidome is further complicated by the diverse incorporation of $\mathrm{N}$ acylated fatty acids (FA) that vary in chain length and degree of saturation. Although the head group of dihydroceramide and ceramide is a single hydroxyl moiety, glycosphingolipids contain polar sugar residues (i.e., glucose and galactose) and sphingomyelins have a phosphocholine head group. In an additive manner, gangliosides are composed of a glycosphingolipid containing one or more sialic acids (e.g., $\mathrm{N}$-acetylneuraminic acid).

The properties of sphingolipids remained largely unknown for a century until the recent advancement of analytical lipidomic technologies. Although sphingolipids are structural components of membranes, we now recognize that they are involved in the regulation of cell growth, differentiation, and apoptosis (Hannun and Obeid, 2008). Moreover, ceramide has emerged as a biomarker for metabolic diseases because of its pathogenic role in the development of type 2 diabetes mellitus (T2DM), nonalcoholic fatty liver disease (FLD), and cardiovascular disease in rodent models and humans (Borodzicz et al., 2015). Unfortunately, our understanding of sphingolipid biology and the role of ceramide in dairy cattle was rudimentary and limited to the recognized presence of sphingolipids within the milk fat globule membrane (Lopez et al., 2008), the considered importance of ceramide to promote the hardness of hooves (Higuchi et al., 2005), and the abil- 
ity of the maize-based mycotoxin fumonisin to inhibit sphingolipid synthesis in livestock including dairy calves (Gilchrist, 1997; Mathur et al., 2001). The objective of this review was to summarize a recent body of work that defines sphingolipid biology in dairy cattle. The role of ceramide is considered to refine our understanding of hepatic lipid biology, nutrient partitioning, and lactation physiology. Scientific questions that challenge contemporary theory are proposed with the intent to advance our understanding of dairy cattle biology.

\section{CERAMIDE SYNTHESIS}

The unique structural attributes of sphingolipids appear to influence their bioactive properties; therefore, the network of anabolic and catabolic pathways that converge on sphingolipids may influence their structure and function. Because ceramide is a precursor for all sphingolipids and widely considered the primary bioactive sphingolipid of interest within the context of insulin resistance observed in nonruminants (Chavez and Summers, 2012), research has focused on major metabolic routes that generate ceramide, including the de novo synthesis, sphingomyelinase, and salvage pathways (Figure 1). These pathways are tightly controlled and highly conserved in mammals (Pewzner-Jung et al., 2006; Zeidan and Hannun, 2007). The synthesis of ceramide has an important role considering that complex dietary sphingolipids are degraded in the mammalian small intestine (Nilsson and Duan, 2006).

DE NOVO SYNTHESIS PATHWAY

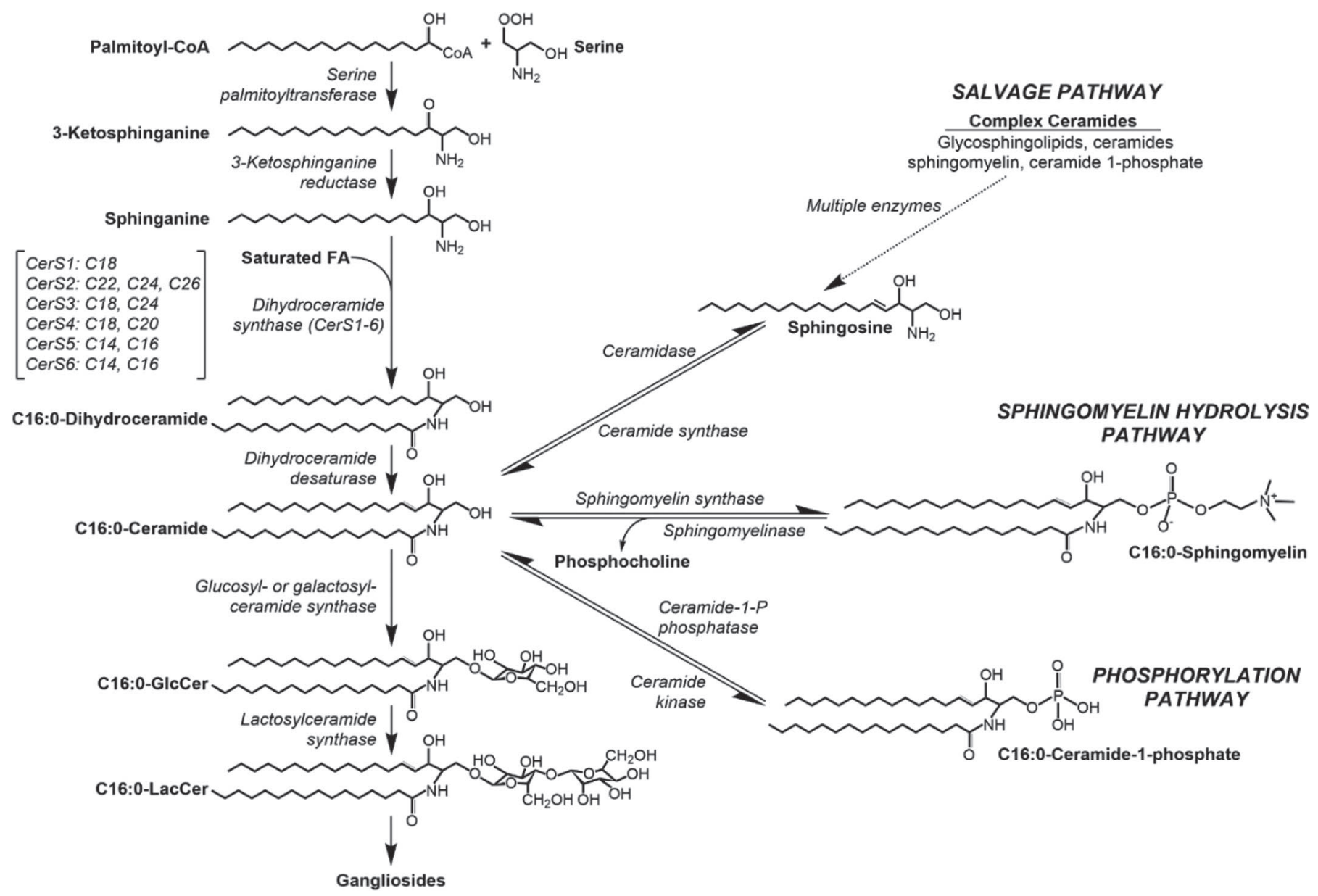

Figure 1. Pathways of ceramide synthesis, degradation, and modification. The synthesis of ceramide is controlled by de novo synthesis from primarily saturated fatty acids (FA), the hydrolysis of sphingomyelin, which forms phosphocholine as a byproduct, or the recycling of complex sphingolipids. The acyl-chain composition of ceramide is controlled by dihydroceramide synthase (commonly called ceramide synthase; CerS). The fatty acyl-CoA preferred by each CerS isoform is denoted in brackets (Levy and Futerman, 2010). For illustrative purposes, only C16:0 -linked sphingolipids are presented. Glycosphingolipids illustrated include monohexosylceramides (GlcCer; glucosylceramide shown) and lactosylceramides (LacCer). Modified from Rico et al. (2015a) with permission. 


\section{De Novo Synthesis Pathway}

The coordinated de novo synthesis of ceramide is initiated by serine palmitoyltransferase (SPT), which catalyzes a condensation reaction between saturated palmitoyl-CoA and the NEAA serine. The product is 3-ketodihydrosphingosine, which is transformed into dihydrosphingosine by the actions of 3-ketodihydrosphingosine reductase. Dihydrosphingosine is further acylated by the actions of dihydroceramide synthases, which are commonly called longevity assurance genes or ceramide synthases (CerS). Located in the cytoplasmic leaflet of the endoplasmic reticulum (Mandon et al., 1992), CerS has an important role because 6 CerS isoforms (CerS1-6) have been discovered (Levy and Futerman, 2010). The type of fatty acyl-CoA selected is influenced by which CerS involved. For instance, CerS2 prefers very-long-chain (VLC) fatty acyl-CoA (e.g., C22:0 and $\mathrm{C} 24: 0$ acyl-CoA), whereas CerS6 predominantly utilizes palmitoyl-CoA (Figure 1). The biochemical activity of CerS and the variable CerS expression profiles across tissues explain why the acyl composition of sphingolipids is not uniform and illuminate the unique biological functions that are attributed to specific ceramide species. Notably, CerS2 primarily controls the synthesis of VLC ceramides in gluconeogenic liver and kidney tissues (Mullen et al., 2012). De novo ceramide synthesis concludes with the NADPH-dependent desaturation of dihydroceramide by dihydroceramide $\Delta^{4}$-desaturase. The resulting ceramide may be utilized by glucosylceramide or galactosylceramide synthase to form monohexosylceramide (i.e., GlcCer or GalCer, respectively) or transformed into sphingomyelin in a reaction controlled by sphingomyelin synthase (Bartke and Hannun, 2009).

\section{Sphingomyelinase Pathway}

The hydrolysis of sphingomyelin generates ceramide and phosphocholine in a reaction catalyzed by sphingomyelinase (SMase; Figure 1). Major types of SMase that vary in their optimal $\mathrm{pH}$ and cellular location include lysosomal and secretory acid SMase (A-SMase), and $\mathrm{Mg}^{2+}$-dependent neutral SMase (N-SMase; Marchesini and Hannun, 2004). Lysosomal and secretory A-SMase are encoded by the same gene but have unique differences in their oligosaccharide structures. Moreover, lysosomal and secretory A-SMase contain several highly conserved zinc-binding motifs and share a pH optima between 4.5 and 5.0 (Goñi and Alonso, 2002). Only secretory A-SMase requires exogenous $\mathrm{Zn}^{2+}$ for functionality (Schissel et al., 1998). Neutral $\mathrm{Mg}^{2+}$-dependent SMase are integral membrane proteins that have a $\mathrm{pH}$ optima near 7.4 and require phosphati- dylserine for catalytic function (Rao and Spence, 1976; Hofmann et al., 2000). The expression of lysosomal A-SMase and $\mathrm{Mg}^{2+}$-dependent N-SMase appears to be ubiquitous in mammalian tissues (Goñi and Alonso, 2002). Two other forms of SMase that have received less attention include $\mathrm{Mg}^{2+}$-independent N-SMase and alkaline SMase (Ghosh et al., 1998; Duan, 2006), the latter being localized to the intestinal mucosa where it may aid in the digestion of dietary sphingomyelin (Cheng et al., 2002).

\section{Salvage Pathway}

Otherwise known as the sphingolipid recycling pathway, the salvage pathway involves the catabolic degradation of complex sphingolipids and glycosphingolipids in acidic late endosomes and lysosomes. The biochemical breakdown requires key enzymes including A-SMase, an array of enzymes that remove monosaccharides and sialic acids (e.g., glucosylceramidase and sialidase), and acid ceramidase, which transforms ceramide into sphingosine and free FA. Whereas dihydrosphingosine is primarily generated by the de novo synthesis pathway, sphingosine appears to be solely derived from sphingolipid recycling. Free sphingosine is reutilized to form ceramide by the actions of CerS, or phosphorylated by sphingosine kinase and targeted for degradation (Smith and Merrill, 1995). The regeneration of sphingolipids by the salvage pathway is recognized as energetically favorable and a major contributor to the overall turnover of glycosphingolipid gangliosides (Tettamanti et al., 2003).

\section{CERAMIDE AND INSULIN RESISTANCE IN NONRUMINANTS}

The development of lipotoxicity and ectopic lipid deposition causes insulin resistance in nonruminants experiencing metabolic disease caused by overnutrition and obesity (Chavez and Summers, 2012). Although the metabolic fate of FA is either catabolic or anabolic, lipotoxicity favors the partitioning of FA away from mitochondrial $\beta$-oxidation and toward FA re-esterification in the form of triacylglycerol (TAG). Indeed, mitochondrial FA overload and incomplete FA oxidation contributes to skeletal muscle insulin resistance (Koves et al., 2008; Bell et al., 2010), and TAG accrual in liver and skeletal muscle is apparent in obese individuals experiencing chronic hyperlipidemia and impaired insulin action (Borén et al., 2013). Lipotoxicity also promotes the formation of bioactive signaling molecules called lipid mediators that directly interfere with insulin signaling and peripheral glucose utilization. Ceramide represents a lipid mediator and second messenger that 
has been extensively evaluated in biomedical research focused on defining the mechanisms of T2DM, nonalcoholic FLD, and cardiovascular disease (Chavez and Summers, 2012).

Over the past 2 decades, the lipotoxic effects of excess ceramide have been well characterized. Initial work studying diabetic mechanisms in obese $f a / f a$ Zucker Diabetic Fatty rats confirmed that the overproduction of ceramide in fat-laden pancreatic islets and the inhibition of SPT within the de novo synthesis pathway prevented islet apoptosis in favor of insulin production (Shimabukuro et al., 1998a,b; Unger, 2002). Summers and coworkers (1998) demonstrated that ceramide inhibited the phosphorylation and activation of anti-apoptotic protein kinase B (AKT) within the insulin-signaling cascade to reduce glucose transporter (GLUT)-4 translocation to the plasma membrane in murine 3T3-L1 adipocytes (Figure 2). Subsequent work using $\mathrm{C} 2 \mathrm{C} 12$ myotubes confirmed that palmitate and other SFA [i.e., stearate (C18:0), arachidate (C20:0), and lignocerate (C24:0)] blocked insulin signaling via ceramide-dependent mechanisms involving AKT inactivation (Chavez et al., 2003; Chavez and Summers,
2003). These in vitro findings were corroborated by the discovery of C16:0- and C24:0-ceramide enrichment in skeletal muscle of obese diabetic patients (Adams et al., 2004). The inhibition of de novo ceramide synthesis ameliorated SFA and obesity-induced insulin resistance in rodents (Holland et al., 2007). The current consensus is that ceramide accumulation in skeletal muscle tissue perturbs insulin sensitivity in the presence of SFA oversupply (Adams et al., 2004; Bruce et al., 2013; Summers and Goodpaster, 2016). The focus on skeletal muscle is merited because it represents the primary mammalian tissue for glucose utilization (Vernon et al., 1990; DeFronzo and Tripathy, 2009; De Koster and Opsomer, 2013); however, adipose tissue ceramide accrual also develops with weight gain and high-fat diet consumption (Shah et al., 2008). In addition, ceramide has been shown to promote lipolysis with impaired insulin action in murine adipocytes (Mei et al., 2002).

Although ceramide is involved in the progression of insulin resistance with obesity, it should be mentioned that the mechanisms of the condition are multifaceted, and ceramide may not be the sole mediator of insulin antagonism (Petersen and Jurczak, 2016; Summers and

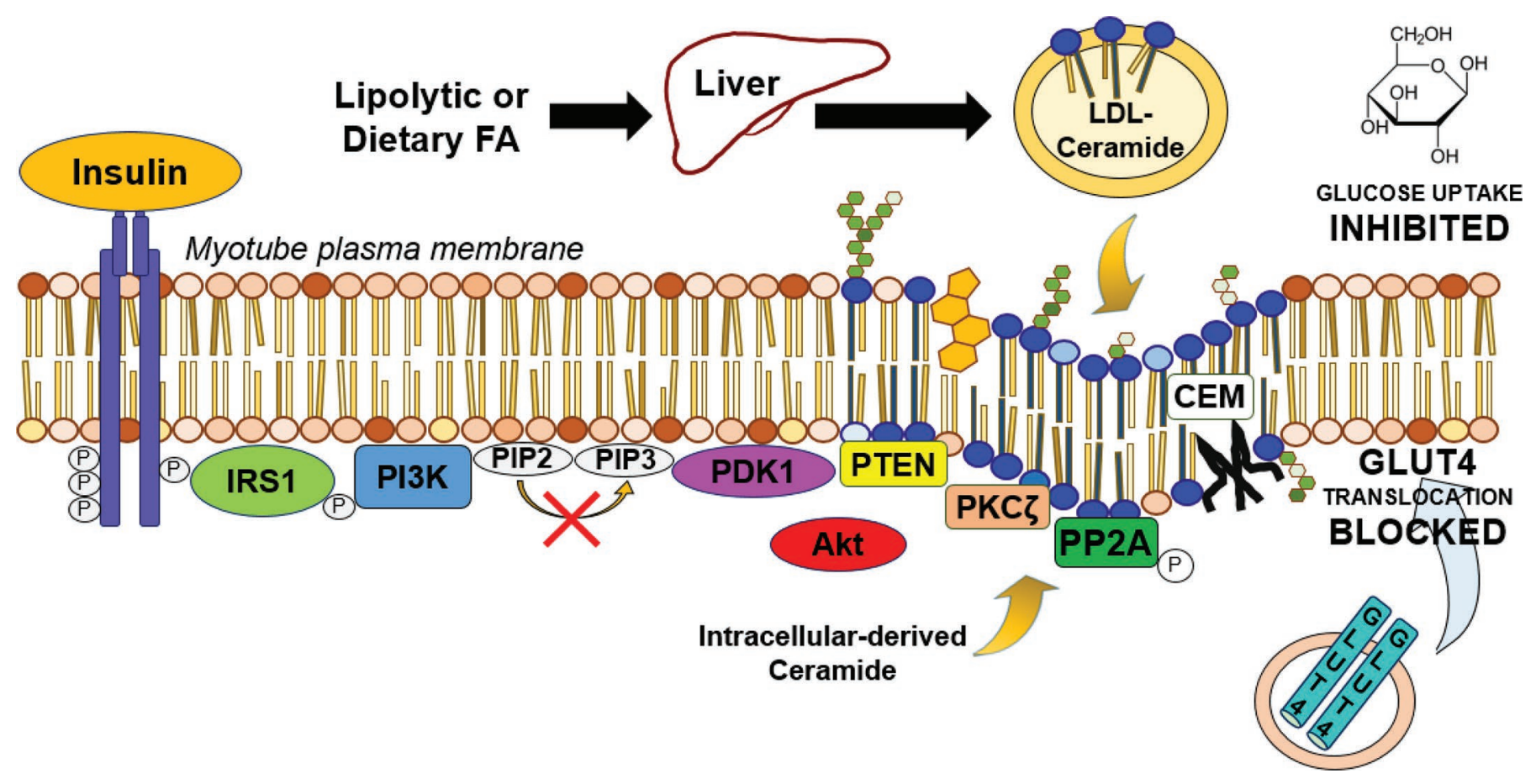

Figure 2. Mechanisms of ceramide action on insulin signaling. The reduction of insulin sensitivity by ceramide action can be attributed to its action on proteins of the insulin-signaling pathway involved in phosphorylation and dephosphorylation events as follows: (1) lipolytic- or dietary-derived fatty acids (FA) increase hepatic ceramide synthesis and secretion; (2) ceramide aggregates in caveolin-enriched microdomains (CEM); (3) ceramide recruits phosphatase and tensin homolog (PTEN) and protein kinase C zeta (PKC C) within CEM, and activates phosphatidylinositol 4,5-bisphosphate (PP2A); (4) phosphatidylinositol (3,4,5)-trisphosphate (PIP3) formation and protein kinase B (AKT) phosphorylation (i.e., activation) are inhibited; (5) insulin-stimulated glucose transporter-4 (GLUT4) translocation and glucose uptake are suppressed. LDL-ceramide = low-density lipoprotein-ceramide; IRS1 = insulin receptor substrate 1, PI3K = phosphatidylinositol-4,5-bisphosphate 3-kinase; PDK1 = phosphoinositide-dependent kinase-1; PIP2 = phosphatidylinositol $(4,5)$-bisphosphate. 
Goodpaster, 2016). Specifically, lipotoxicity and insulin resistance also develop with hepatic and skeletal muscle diacylglycerol accrual (Corcoran et al., 2007). Diacylglycerol is another type of lipid mediator that inhibits insulin-stimulated glucose transport via activation of protein kinase $\mathrm{C}(\mathbf{P K C})$ and inactivation of insulin receptor substrate 1 (IRS1; Itani et al., 2002; Erion and Shulman, 2010). However, the skeletal muscle role of diacylglycerol has been contested, especially considering that muscle diacylglycerol concentrations are elevated in endurance-trained athletes with high insulin sensitivity compared with observations in obese and sedentary individuals (Amati et al., 2011; Summers and Goodpaster, 2016).

The mechanisms that ceramide uses to inhibit insulin signaling are well characterized in nonhuman primates and rodents. First, ceramide downregulates insulin signaling by inhibiting insulin-stimulated AKT serine phosphorylation (i.e., Ser-473; Summers et al., 1998; Schubert et al., 2000). However, the antagonistic behavior of ceramide may not completely rely on AKT suppression. For instance, the ability of ceramide to inhibit insulin-stimulated glucose transport depends on its recruitment within caveolin-enriched microdomains located within the plasma membrane (Blouin et al., 2010). Insulin antagonism by ceramide may also involve the activation of $\mathrm{PKC} \zeta$, phosphatase and tensin homolog (PTEN), and protein phosphatase 2A (PP2A; Figure 2; Hajduch et al., 2008; Blouin et al., 2010; Chavez and Summers, 2012). Ceramide-dependent caveolinenriched microdomain-recruitment of $\mathrm{PKC} \zeta$ promotes the phosphorylation of AKT at Thr-34 to inhibit function (Powell et al., 2003). In contrast, the activation of PTEN transforms phosphatidylinositol triphosphate to phosphatidylinositol bisphosphate to downregulate phosphatidylinositol 3-kinase (PI3K) signal transduction, and PP2A dephosphorylates AKT at Thr-308 and Ser-473. In parallel, ceramide may also deactivate IRS1 via Ser-307 phosphorylation (Hage Hassan et al., 2016).

Although the de novo synthesis of ceramide within tissues is a potential contributor to localized ceramide accrual and insulin resistance, recent work by Boon et al. (2013) and Watt et al. (2012) provides support for the ability of liver-derived lipoprotein ceramide to antagonize insulin action in peripheral tissues. As demonstrated in rats intravenously infused a TAG emulsion or HepG2 liver cells cultured with palmitate, the liver is able to detect and secrete de novo synthesized ceramides in response to FA oversupply (Watt et al., 2012). Hepatic ceramide accumulation is observed in rodent models of FLD and may develop in obese diabetic humans with nonalcoholic FLD (Pagadala et al., 2012). Elevations in hepatic ceramide synthesis and secretion likely depend on steatosis in the presence of a simultaneous inflammatory insult (Pagadala et al., 2012 ) and the actions of microsomal triglyceride transfer protein (Iqbal et al., 2015). In human circulation, ceramides are predominantly found within low-density lipoproteins (LDL; $60 \%$ of total lipoproteins; Wiesner et al., 2009); although the proportion of ceramide found within liver-secreted very-low-density lipoproteins (VLDL) increases with fasting ( $\sim 39$ vs. $48 \%$ of ceramide found within VLDL and LDL, respectively; Wiesner et al., 2009). Prior observations suggest that LDL ceramide enrichment occurs within LDL aggregates via the hydrolysis of LDL-sphingomyelin or transfer of preexisting ceramide from cells (Schissel et al., 1996). Watt and colleagues (2012) hypothesize that hepatocyte de novo synthesis of ceramide may also explain changes in VLDL and LDL ceramide.

The focus on LDL ceramide is important because their concentrations are elevated in diabetic humans (Haus et al., 2009; Boon et al., 2013). The intravenous infusion of LDL containing C24:0-ceramide, the most abundant ceramide in circulation, reduces whole-body and skeletal muscle 2-deoxyglucose (2DOG) clearance in mice (Boon et al., 2013). In the same study, C24:0-ceramide concentrations tended to be elevated in fractionated plasma membranes; however, C24:0 -ceramide levels were not enriched in whole skeletal muscle. Similar outcomes were observed for mice intravenously infused LDL C16:0-ceramide. The translocation of ceramide from LDL to the plasma membrane may involve LPS receptor CD14, which provokes clustering of co-receptors in membrane microdomain rafts (Pfeiffer et al., 2001). Once in the plasma membrane, ceramide likely accumulates in caveolin-enriched microdomains (Blouin et al., 2010). Subsequent experiments confirmed the inhibition of insulin-stimulated 2DOG uptake, AKT phosphorylation, and GLUT4 translocation in L6 muscle cells incubated with C16:0- or C24:0 -ceramide (Boon et al., 2013). Interestingly, the origin of ceramide may not matter when we consider the potential ability of ceramide to "flip-flop" across the phospholipid bilayer of the plasma membrane (Kinnunen and Holopainen, 2002). This action suggests that extracellular- and intracellular-derived ceramide may work in unison to inhibit skeletal muscle insulin sensitivity during lipotoxicity. Interestingly, extracellular ceramide within LDL does to appear to modulate insulin sensitivity in murine white adipose tissue or 3T3-L1 adipocytes (Boon et al., 2013).

In CerS2 haploinsufficient mice (Raichur et al., 2014) or CerS6-deficient mice (Turpin et al., 2014), evidence suggests that C16:0-ceramide promotes obesity-induced insulin resistance. Similarly, mice with CerS1 deficiency 
exhibit reduced muscle C18:0-ceramide concentrations and improved systemic glucose homeostasis (TurpinNolan et al., 2019), whereas VLC ceramides (i.e., C22:0- and C24:0-ceramide) serve a protective role (Raichur et al., 2014; Tippetts et al., 2018). This argument is complicated in light of evidence in mice demonstrating the ability of C24:0-ceramide within LDL to reduce insulin-stimulated glucose utilization (Boon et al., 2013) and the observation that VLC ceramides play a lipotoxic role in mediating mitochondrial dysfunction and oxidative stress (Law et al., 2018). It seems reasonable to infer that long-chain and VLC ceramides have lipotoxic potential, but their effects on metabolism likely depend on type of pathology, tissue examined, and total ceramide status of the animal.

Chronic inflammation is a key component of insulin resistance caused by overnutrition (Lionetti et al., 2009; Caputo et al., 2017). Ceramide supply and inflammation are tightly intertwined. In detail, the proinflammatory cytokine tumor necrosis factor- $\alpha$ (TNF) is an inhibitor of insulin signaling (Borst, 2004; Nguyen et al., 2005). Tumor necrosis factor- $\alpha$ inhibits the insulin-dependent tyrosine phosphorylation of insulin receptor and IRS1 (Peraldi et al., 1996). The antagonistic actions of TNFo also involve the hydrolysis of sphingomyelin to form ceramide by A- and N-SMase induction (Peraldi et al., 1996; Peraldi and Spiegelman, 1998; Rozenova et al., 2010). This is of particular interest because endotoxin (i.e., LPS) and saturated palmitate activate SMase via mechanisms that involve toll-like receptor-4 signaling and $\mathrm{TNF} \alpha$ (Wong et al., 2000; Holland et al., 2011a). Moreover, inflammation-mediated secretory-SMase activation stimulates LDL-sphingomyelin hydrolysis, which may also contribute to circulating ceramide accrual during insulin resistance (Schissel et al., 1998). In a feedback manner, SMase activation and ceramide may provoke inflammation by stimulating the production of inflammatory cytokines including IL-6 (Ballou et al., 1996). Indeed, ceramide augments TNF $\alpha$ release from macrophages, which has implications for individuals that experience adipose tissue macrophage infiltration with high liver fat content (Kolak et al., 2007; Schilling et al., 2013).

The discovery of ceramide as an insulin antagonist triggered numerous studies to assess sphingolipid as a metabolic disease biomarker in humans. Kremer et al. (1975) first demonstrated the accrual of GlcCer in plasma collected from diabetic patients. Three decades later, Haus and coworkers (2009) demonstrated plasma ceramide (C18:0, C20:0, C24:1, and C24:0) accrual in T2DM patients. They also observed that plasma ceramide levels were inversely related to insulin sensitivity but positively associated with circulating $\mathrm{TNF} \alpha$ levels. Plasma ceramide accumulation is also observed in female children and adolescents with T2DM and suppressed levels of circulating adiponectin (Lopez et al., 2013). As mentioned earlier, plasma LDL ceramide concentrations are elevated in obese diabetic humans (Boon et al., 2013). Suggesting prognostic potential, plasma C16:0-, C22:0-, and C24:0-ceramide concentrations were elevated in prediabetic and diabetic Rhesus Macaque monkeys (Brozinick et al., 2013). In addition, increased plasma levels of C18:0 deoxysphinganine, a signature of SPT activation, were observed before the onset of diabetes. Such relationships have spurred interest in developing nutritional and pharmacological approaches to control ceramide supply. For instance, we have identified a nutritional therapy that reduces circulating ceramides in overweight young adults (Mathews et al., 2017), and the development of effective and safe oral SPT inhibitors is being pursued (Genin et al., 2016; Adachi et al., 2018).

\section{SPHINGOLIPID BIOLOGY IN THE DAIRY COW}

\section{Sphingolipids in Milk}

Our knowledge of sphingolipids in ruminants has been historically limited to the observation that dairy products are a major source of sphingolipids in the human diet (Vesper et al., 1999). Unlike TAG, which locate predominantly in the core of milk fat globules, sphingolipids co-locate with glycerophospholipids in the milk lipid globule membrane (Lopez et al., 2008). Membrane sphingolipids are believed to prevent globules from coalescing, to act as emulsion stabilizers, and to be critical for the formation and maintenance of the globular membrane structure (Jensen, 2002; Heid and Keenan, 2005). In terms of composition, sphingomyelin predominates ( $\sim 75 \%$ of total sphingolipids; Christie et al., 1987), whereas the concentrations of ceramide, GlcCer, LacCer, and gangliosides are far more limited (Jensen, 2002). Similar to TAG, milk sphingolipids from ruminants are compositionally unique with diverse fatty acyl chains with varying degrees of saturation, hydroxylation, and glycosylation. Comparable to human milk (Bouhours and Bouhours, 1981), the major acyl chains in bovine milk sphingolipids include 16-, 18-, 22-, and 24-carbon units (Morrison and Hay, 1970). The presence of sphingolipids in milk has sparked renewed interest in dairy because of the discovery of anticarcinogenic and anti-inflammatory properties of ceramides and sphingomyelins, respectively (Ogretmen and Hannun, 2004; Norris et al., 2017). Moreover, milk sphingomyelin is a source of dietary phosphocholine, which may benefit neonatal development (Zeisel et al., 1986). 


\section{Ceramide Accrual in the Early-Lactation Cow}

The transition from gestation to lactation represents a metabolic challenge for high-producing dairy cows. Glucose demand is high for the synthesis of milk lactose, the osmotic regulator of milk volume. To meet this demand, the cow relies on 2 adaptations: hypoinsulinemia and modified peripheral tissue response to insulin (Baumgard et al., 2017). Hypoinsulinemia is caused by reduced glucose-stimulated pancreatic insulin secretion (Rhoads et al., 2004). In addition, insulin reduces whole-body and skeletal muscle glucose uptake in a dose-response manner (Vernon et al., 1990). In adipose tissue, a reduction in insulin action supports lipolysis (Vernon and Taylor, 1988). Although lipolysis serves a purpose to provide FA substrate for oxidative metabolism and milk TAG synthesis, accelerated body fat mobilization provokes hepatic FA uptake, steatosis, ketogenesis, and infertility (Rukkwamsuk et al., 2000; Bobe et al., 2004; Duffield et al., 2009). These outcomes are routinely observed in cows with heightened prepartum adiposity (i.e., elevated BCS) and rampant lipolysis (Roche et al., 2009; Zachut et al., 2013).

Based on biomedical research identifying ceramide as a causal agent of insulin resistance in overweight and diabetic nonruminants experiencing SFA surplus (Summers, 2006; Haus et al., 2009; Chavez and Summers, 2012) and the role of insulin antagonism and lipolysis in the postpartum cow, in our initial work we quantified peripartal changes in plasma ceramides collected from cows classified prepartum as lean or overweight $(\mathrm{BCS}<3.0$ and $>4.0$, respectively; $\mathrm{d}-28$ through d 4, relative to calving; Rico et al., 2015a). Independent of prepartum adiposity phenotype, we observed a progressive accumulation of plasma ceramides as cows transitioned from pregnancy to lactation. Overweight cows experienced greater body weight loss and circulating free FA and ceramide concentrations postpartum compared with lean cows. The majority of plasma ceramides and GlcCer measured were positively associated with circulating free FA and inversely related to estimated systemic insulin sensitivity (i.e., the Revised Quantitative Insulin Sensitivity Check Index; Holtenius and Holtenius, 2007). The strongest correlations were observed for VLC ceramides including highly abundant C22:0- and C24:0-ceramide. This finding was interesting because the intravenous infusion of C24:0 -ceramide within LDL into C57BL/6J mice reduced whole-body and skeletal muscle insulin-stimulated 2DOG uptake (Boon et al., 2013). Our inaugural study supported a role for ceramide in the development of insulin antagonism in postpartum cows that mobilize body fat. Our observations also supported the expected substrate-product relationship that drives de novo ce- ramide synthesis (Figure 1; Watt et al., 2012), whereby lipolytic-derived palmitic acid is utilized by SPT to form 3-ketosphinganine or elongated by elongases for utilization by CerS to form ceramide (Ohno et al., 2010). Subsequent sample analyses demonstrated that ceramide accrual developed with plasma fatty acylcarnitine accumulation, which might indicate the partitioning of FA away from mitochondrial $\beta$-oxidation and toward sphingolipid synthesis (Yang et al., 2009; Rico et al., 2018b).

To independently confirm our findings in a separate cohort and expand our understanding of sphingolipid biology in periparturient cows, we conducted a more complete investigation of the temporal changes in plasma, liver, and skeletal muscle sphingolipid levels compared with hepatic lipid deposition and systemic insulin and glucose tolerance during the totality of the transition period ( $\mathrm{d}-21$ through $\mathrm{d} 21$, relative to calving; Rico et al., 2017b). Because of uncertainties associated with the application of insulin sensitivity indices in transition cows (Mann et al., 2016), we chose to utilize more direct measures, including glucose and insulin tolerance testing, to assess systemic glucose utilization. In confirmation of our earlier work (Rico et al., 2015a), plasma ceramides and GlcCer concentrations increased at the onset of lactation, with more pronounced elevations observed in cows with elevated prepartum adiposity in association with plasma free FA concentrations. Plasma ceramide levels were also positively correlated with liver lipid content. Although changes in hepatic ceramide levels were minimal during the transition, hepatic C24:0-ceramide levels did increase as overweight cows transitioned. The hepatic ceramide profile reflected plasma (Figure 3), and positive associations were identified between hepatic and plasma ceramide levels, which further supported the role of the liver as a primary source of circulating ceramides.

Because we were cognizant that enhanced de novo ceramide synthesis may not be the only explanation for plasma ceramide accrual, we investigated the possibility that sphingomyelin hydrolysis by SMase activation may be at play. This inquiry was warranted because inflammatory cytokines activate SMase in nonruminants and the transition cow experiences inflammation (Peraldi et al., 1996; Bertoni et al., 2008; Sordillo and Raphael, 2013). In our investigations (Rico et al., 2017b, 2018b), circulating phosphocholine-containing sphingomyelins, including C16:0-, C22:0-, and C24:0 -sphingomyelin, were lowest at parturition in all cows. Plasma reductions in C18:1- and C20:1-sphingomyelin were greater for overweight cows compared with lean cows. Although these findings support the possibility that inflammation-mediated SMase activation may also promote ceramide accrual in postpartum cows, 
especially in overweight cows that may preferentially experience inflammation (O'Boyle et al., 2006), the apparent reduction in circulating sphingomyelin may be an artifact of reduced DMI and low dietary choline bioavailability (Neill et al., 1979; Sharma and Erdman, 1989; Rico et al., 2017b). Nevertheless, plasma and hepatic sphingolipidome remodeling developed with C16: 0-ceramide accrual in skeletal muscle postpartum independent of late-gestation adiposity status. This is of potential significance because C16:0- and C18:0-ceramide are believed to mediate skeletal muscle insulin resistance in nonruminants (Boon et al., 2013; Tonks et al., 2016). Although we did not evaluate skeletal muscle insulin action, plasma C24:0-ceramide and skeletal muscle C16:0-ceramide levels were inversely related to glucose clearance rate and insulin-stimulated reductions in glucose following an insulin challenge postpartum, respectively (Rico et al., 2017b; Figure 4A). Similar results were observed for plasma C18:0-ceramide (Figure 4B). Additionally, plasma C16:0-GlcCer concentrations were inversely related to glucose-stimulated reductions of free FA following a glucose challenge. Although data from Rico et al. (2015a, 2017b) supported the possi- bility that ceramides contribute to insulin antagonism during early lactation, controlled trials were needed to assess the effects of hyperlipidemia on ceramide supply.

\section{Lessons Learned from the Controlled Induction of Hyperlipidemia}

The oversupply of free FA enhances hepatic de novo ceramide synthesis and secretion in nonruminants (Watt et al., 2012). To mimic hyperlipidemia during obesity, lean humans and rats underwent an acute intravenous infusion of plant-based TAG emulsion, which resulted in increased circulating FA and ceramides in both groups and promoted hepatic ceramide accumulation in rats (Watt et al., 2012). Considering that palmitic acid is the principal substrate for de novo ceramide synthesis (Figure 1), Watt and coworkers (2012) confirmed that palmitate incorporation into intracellular and extracellular ceramide is dose- and time-dependent in HepG2 liver cells. Considering these findings, we sought to confirm the importance of hyperlipidemia for promoting hepatic and plasma ceramide accrual using nonpregnant and nonlactating dairy cows continuously infused with

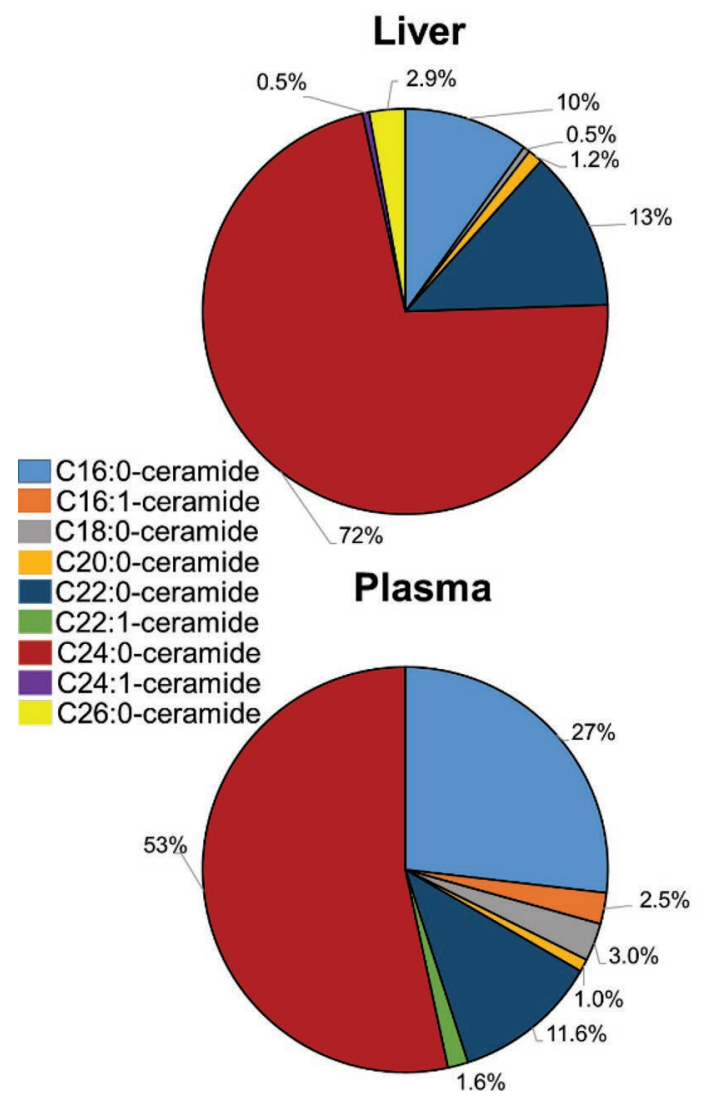

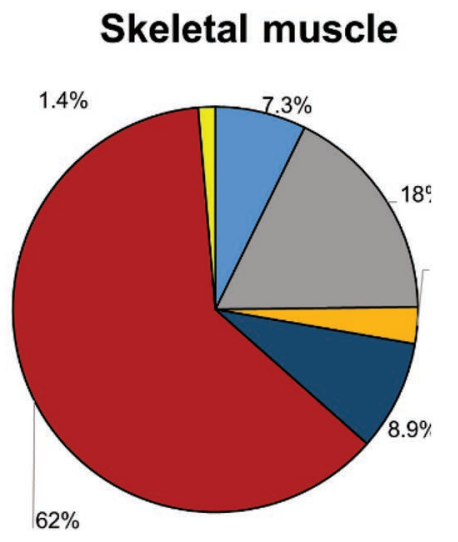

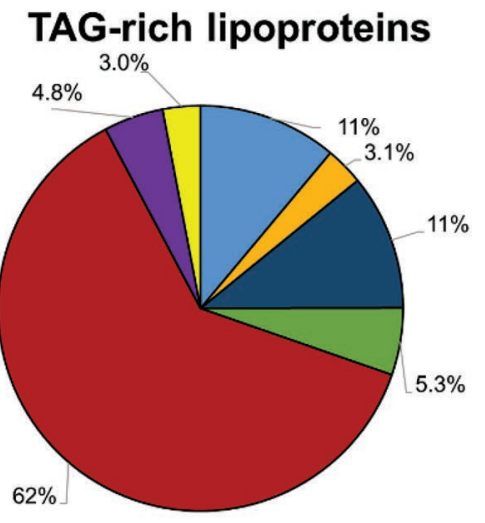

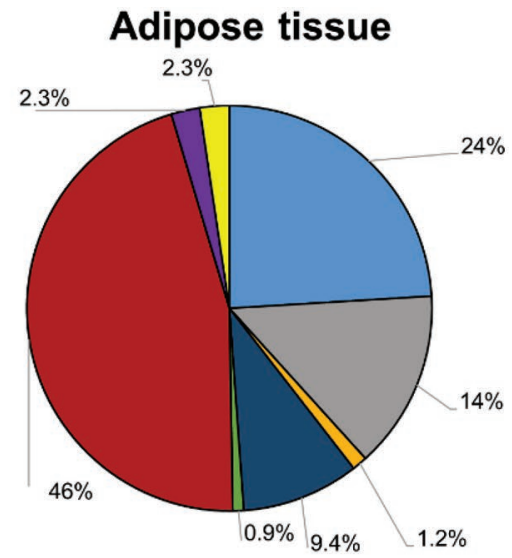

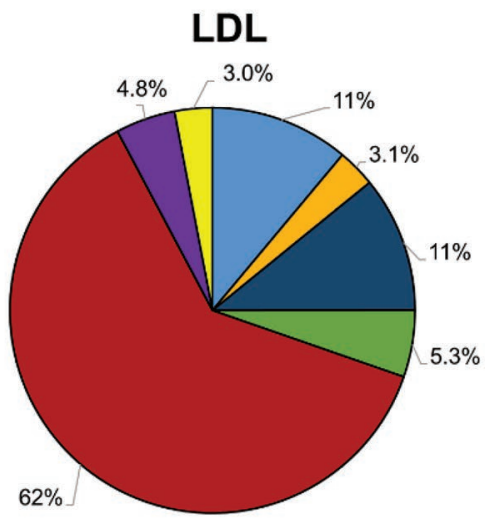

Figure 3. Ceramide compartment profiles in Holstein dairy cows. Fatty acyl chain profiles of ceramides in liver, skeletal muscle, adipose tissue, plasma, low-density lipoprotein (LDL), and triacylglycerol (TAG)-rich lipoproteins. 
an identical TAG emulsion delivered intravenously over 16 h (Caixeta et al., 2017; Rico et al., 2018c). Intravenous TAG infusion raised circulating free FA and fibroblast growth factor 21 (FGF21) concentrations and hepatic TAG levels and robustly elevated circulating and hepatic ceramides and GlcCer. Fibroblast growth factor 21 can induce adiponectin secretion to suppress ceramide production (Holland et al., 2013); however, TAG infusion does not increase circulating adiponectin concentrations in anabolic cows (Staiger et al., 2002; Krumm et al., 2017). In nonpregnant, nonlactating cows, the inability of adiponectin secretion to respond
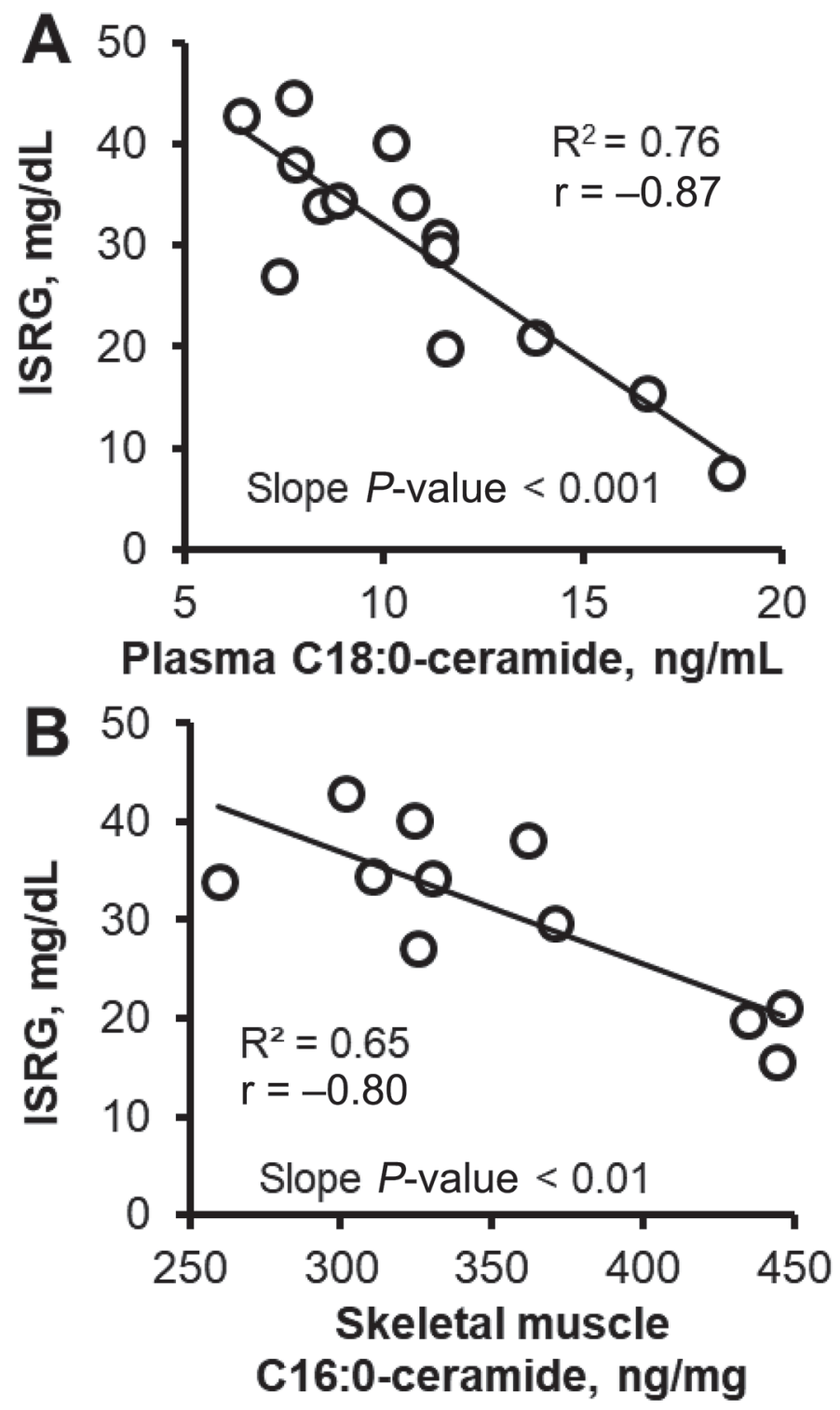

Figure 4. Ceramide concentrations are inversely related to insulinstimulated glucose disposal in lactating dairy cows. (A) Regression analysis of plasma C18:0-ceramide and (B) skeletal muscle C16:0 -ceramide against insulin-stimulated reductions in plasma glucose (ISRG) in Holstein cows during postpartum (d 5 of lactation; $\mathrm{n}=14$ ). to increases in FGF21 and prevent ceramide accrual is interesting. It is likely that the increase in circulating FA concentrations supported de novo ceramide synthesis solely because of increased substrate supply. Indeed, we observed marked increases in $\mathrm{C} 22: 0-$ and $\mathrm{C} 24: 0$ -dihydroceramide concentrations. Additionally, hepatic CerS2 mRNA expression was enhanced by TAG infusion, which is significant because CerS2 controls the de novo synthesis of VLC ceramides (Figure 1) and TAG infusion did not modify plasma sphingomyelin levels. In clinically healthy dairy cows in positive energy balance and challenged by surplus FA, we concluded that hepatic de novo ceramide synthesis - not sphingomyelin hydrolysis - was the predominant driver of ceramide accrual. In support, the supplementation of bovine neonatal hepatocytes with palmitic acid increased intracellular ceramide concentrations, and this effect was completely reversed by the inhibition of SPT with myriocin (McFadden et al., 2018).

To explore the effects of hyperlipidemia in dairy cows experiencing negative energy balance, nonpregnant, nonlactating dairy cows were fed ad libitum or nutrient-restricted (i.e., straw feeding only) for $32 \mathrm{~h}$ (Davis et al., 2017a). We anticipated that the upregulation of adipose tissue lipolysis would increase hepatic saturated palmitic acid uptake and increase ceramide synthesis (Douglas et al., 2007). As expected, nutrient restriction dramatically elevated circulating free FA and enhanced liver lipid content. Simultaneously, serum and hepatic ceramide accumulation developed with nutrient restriction. Comparable to the effect in the transition cow, serum and liver C22:0- and C24:0-ceramide were inversely related to systemic changes in insulinstimulated glucose disposal in nutrient-restricted cows challenged by insulin (i.e., glucose clearance rate and area under the curve following an intravenous glucose challenge) which was not observed for C16:0-, 18:0-, or C20:0-ceramide. In contrast to that in the transition cow, serum and liver C16:0-ceramide increased with the induction of negative energy balance and contributed more to the ceramide pool. These findings suggest that physiological stage may govern hepatic CerS isoform expression and activation, and thus influence the ceramide profile of liver and plasma. Unfortunately, circulating or hepatic dihydroceramides or sphingomyelins were not measured in Davis et al. (2017a), which means that the contributions of de novo ceramide synthesis versus sphingomyelin hydrolysis could not be distinguished. Alternatively, CerS2 regulates FA elongase-1 to ensure coordinated VLC ceramide synthesis (Ohno et al., 2010). We do not know whether the functionality of elongase isoforms changes with stage of physiology. Perhaps an acute feed restriction fails to induce palmitic acid elongation in the nonlactating, nongestating 
cow. Although the physiological differences in ceramide production require further study, our findings suggest that ceramide may represent a link between FA surplus and peripheral insulin resistance observed in Holstein cows (Pires et al., 2007).

\section{Circulating Sphingolipids}

The liver is a major contributor of circulating sphingolipids, as suggested by the close overlap in the compositional profiles of liver and plasma ceramides (Haus et al., 2009; Rico et al., 2018c; Figure 3) and by the rapid increase in plasma ceramides in response to hepatic free FA influx (Watt et al., 2012; Rico et al., 2018c). Indeed, estimates suggest that approximately 75 to $97 \%$ of circulating ceramides are contained within the apolipoprotein B100-containing VLDL and LDL of hepatic origin, with the remainder associated with high-density lipoproteins (Lightle et al., 2003; Wiesner et al., 2009; Hammad et al., 2010). These ceramides are primarily $\mathrm{C} 16: 0-, \mathrm{C} 22: 0-$, and $\mathrm{C} 24: 0$-ceramide in the dairy cow. Interestingly, although ceramide and sphingomyelins are largely contained in secreted VLDL, these sphingolipids do not seem necessary for VLDL secretion (Merrill et al., 1995). Ceramide incorporation into nascent lipoprotein is mediated by microsomal triglyceride transfer protein via a mechanism similar to that used to incorporate TAG into VLDL (Iqbal et al., 2015). Furthermore, palmitate increases cellular microsomal triglyceride transfer protein levels, which suggests that elevated SFA availability not only upregulates ceramide synthesis but also induces its secretion from liver (Konstantynowicz-Nowicka et al., 2015).

Although the liver represents the major source of circulating ceramides, not all ceramides in plasma can be accounted for by lipoproteins. Indeed, lipoproteindeficient serum contains $\sim 15 \%$ of serum ceramides (Lightle et al., 2003). One possible alternative source is adipose tissue, which has been hypothesized to release ceramides and modulate insulin sensitivity in liver (Holland et al., 2007; Cowart, 2009). A second possibility is that ceramides are shed as cargo from cells within extracellular vesicles (i.e., exosomes) that bud from the plasma membrane as part of intercellular communication mechanisms operating during cell stress conditions such as during lipotoxicity (Trajkovic et al., 2008; Kornek et al., 2012; Yoon et al., 2014).

\section{Dietary Fatty Acids and Ceramide Synthesis}

If ceramide is able to control insulin signaling and glucose utilization by nonmammary tissues, then dietary approaches that modulate ceramide production would be of commercial interest to control lactation.
Certainly, the rumen biohydrogenation of UFA to form nonesterified SFA (i.e., $\sim 65 \%$ of free FA reaching the duodenum are C16:0 and C18:0; Lock et al., 2006) represents a potential substrate for SPT. Although biohydrogenation serves to detoxify UFA (Maia et al., $2007,2010)$, it is intriguing to consider whether the magnitude of rumen biohydrogenation is correlated with ceramide production. Such a relationship would provide the cow with a glucose-sparing mechanism to support milk production when feeding on grasses that contain UFA. Although this remains to be defined, we recognize that rumen-inert fat supplementation (i.e., SFA products) is common on dairy farms, and the dietary supplementation of SFA-enriched fat supplements may favor ceramide synthesis and accumulation. To assess this possibility, a series of in vivo studies were performed to evaluate the effects of palmitic acid feeding compared with no added fat, stearic acid, mediumchain TAG (MCT), palmitoleic acid, and $\alpha$-linolenic acid supplementation.

In mid-lactation low-producing Holstein dairy cows fed a sorghum silage-based TMR, we investigated the effects of feeding a diet containing supplemental palmitic acid at $\sim 4 \%$ of ration DM for 7 wk relative to cows supplemented with soyhulls (Rico et al., 2016). Similar to previous observations (Wang et al., 2010; Piantoni et al., 2013), palmitic acid feeding increased milk and milk fat yields without modifying DMI (Mathews et al., 2016). In support of adipose tissue insulin antagonism, the magnitude of plasma free FA disappearance following an intravenous glucose challenge progressively decreased with palmitic acid supplementation in the absence of changes in systemic glucose tolerance. These outcomes that accompanied palmitic acid supplementation occurred with pronounced elevations in circulating ceramides and GlcCer, whereas lactosylceramide (LacCer) levels were not overtly modified (Rico et al., 2016). Increases were greatest for VLC ceramides including C22:0- and C24:0-ceramide but no changes were observed for C16:0-ceramide. Palmitic acid feeding also increased hepatic ceramide concentrations (e.g., C20:0, C24:0, and total), although the response was less pronounced relative to plasma. Although we describe that CerS2 and CerS6 are likely the predominant controls of hepatic de novo ceramide synthesis in cows (Rico et al., 2018c), palmitic acid feeding reduced CerS2 mRNA expression in liver, perhaps reflecting a compensatory mechanisms to maintain ceramide homeostasis. Alternatively, palmitic acid feeding may not have induced de novo ceramide synthesis but rather activated A-SMase (Jin et al., 2013). Nevertheless, removal of supplemental palmitic acid from the diet immediately restored ceramide levels to those observed in control cows (Rico et al., 2016). 
Of particular interest, palmitic acid feeding prevented the gradual decline in circulating ceramides that was detected in control cows advancing toward late lactation (Figure 5A; Rico et al., 2016). This gradual reduction in circulating ceramides developed concomitantly with a steady decrease in circulating FA levels and increase in plasma insulin concentrations. The observed increase in circulating ceramides during early lactation (Rico et al., 2015a, 2017b) and their decline beyond peak milk production (Rico et al., 2016) suggests that ceramide supply responds in a reciprocal manner as energy balance and insulin sensitivity improve with the progression of lactation. The ability of palmitic acid to augment ceramide synthesis may be a means to maintain glucose-sparing mechanisms to drive lactation after peak milk yield in low-production cows. In support, circulating ceramides were positively correlated with plasma FA, FA area under the curve following a glucose challenge, and milk yield (Rico et al., 2016). Increased nutrient partitioning toward milk with high palmitic acid feeding has also been independently observed in mid-lactation Holstein cows (de Souza et al., 2018) relative to cows fed in the absence of supplemental fat.

Although the restoration of insulin antagonism and nutrient (i.e., glucose and FA) partitioning to support milk and milk fat production later in lactation is desirable, such an outcome during early lactation may exacerbate insulin antagonism to a point where body fat mobilization is further accelerated. Indeed, the cow may produce more milk with a milk FA composition that reflects the lipolytic profile but she might be at increased risk for developing a metabolic disease such as FLD or ketosis. These possibilities require further study; however, recent evidence suggests that palmitic acid feeding (1.5\% of ration DM) enhances body fat mobilization during early lactation (de Souza et al., 2019) compared with a control diet containing no supplemental fat. These palmitic acid-fed early-lactation cows exhibited greater circulating ceramide concentrations (e.g., total and $\mathrm{C} 24: 0$ ) in a positive association with circulating plasma total FA and milk yield (Figure 5B; Davis et al., 2017b). Interestingly, recent work suggests that the partial substitution of dietary palmitic acid with oleic acid increases plasma insulin levels and limits body weight loss during the postpartum (de Souza et al., 2018), relative to feeding palmitic acid alone. The inclusion of oleic acid decreased and increased energy partitioning toward milk and body tissue gain, respectively. Requiring confirmation in cows, these responses may involve the ability of oleic acid to lower ceramide (Jin et al., 2018). Considering that dietary FA feeding appears to modulate lipolysis by using mechanisms that may involve ceramide, it is intriguing to consider whether ceramide might indirectly influence the milk
FA profile. Palmitic acid feeding routinely increases yields of milk fat and 3.5\% FCM (de Souza et al., 2016), and some studies have shown increases in palmitic acid in milk fat but also preformed cis-9 oleic acid (de Souza and Lock, 2018). Palmitic, stearic, and oleic acids are abundant FA found in adipose tissue and a potential source for milk fat production (Rukkwamsuk et al.,
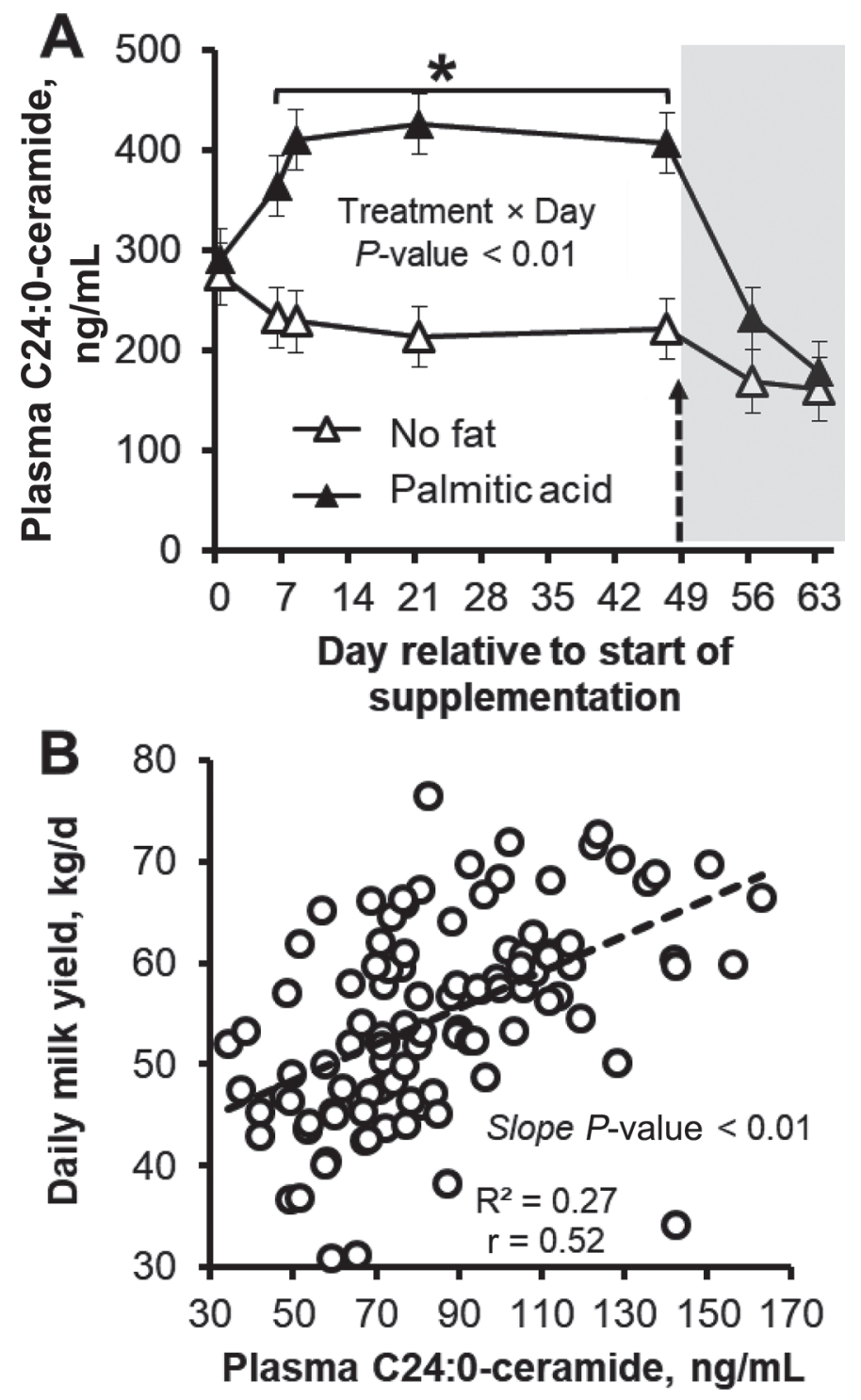

Figure 5. Plasma very-long-chain ceramide concentrations are increased during palmitic acid feeding and are positively associated with milk yield in dairy cows. (A) Plasma concentration of abundant C24:0 -ceramide during palmitic acid feeding in mid-lactation Holstein cows ( $\sim 4 \%$ of ration DM; palm fat composed of $98 \%$ palmitic acid) during (d 0 to 49) and after (d 49 to 63; dotted arrow) treatment, relative to no supplemental fat. Data are presented as least squares means and their standard errors; ${ }^{*} P<0.05$. From Rico et al. (2016). (B) Regression analysis between plasma C24:0-ceramide concentrations and daily milk yield in multiparous Holstein cows during early lactation. Data represent measurements between d 7 and 54 postpartum. Adapted from Davis et al. (2017b). 
2000). Their proportions in milk fat are controlled to maintain fluidity (Chilliard et al., 2000).

Although palmitic acid is the principal substrate for de novo ceramide synthesis, palmitic acid or other FA (most often longer chain SFA) are incorporated by CerS. Moreover, the consumption of PUFA has been shown to decrease ceramide accrual compared with the consumption of SFA (Blachnio-Zabielska et al., 2010). To evaluate, we quantified circulating ceramides in mid-lactation Holstein cows abomasally infused with SFA in the form of palmitic acid, MCT (C8:0/C:10), and stearic acid (Rico et al., 2017a). Although milk yield was not influenced by these treatments, plasma ceramide, GlcCer, and LacCer concentrations were positively associated with plasma total FA and yields of milk and FCM. Even though total FA digestibility was higher for cows infused MCT (Rico et al., 2015b), palmitic acid was more effective at raising plasma palmitic acid and ceramide concentrations relative to MCT and stearic acid (Rico et al., 2017a). We note that the reduced ability of stearic acid to raise plasma ceramides may be explained by lower FA digestibility observed with the infusion of this FA. Moreover, the importance of hepatic elongases to convert stearic acid to VLC FA to generate VLC ceramides in ruminants is unknown. Although this could not be discerned, a positive relationship between circulating free FA and ceramide and elevations in GlcCer concentrations were inversely associated with a lower hepatic expression of apolipoprotein B100 and carnitine palmitoyltransferase-1A (Rico et al., 2017a). These observations suggest that plasma ceramide accrual develops with the downregulation of hepatic lipoprotein assembly and mitochondrial FA oxidation. Such conditions are typical of the postpartum dairy cow experiencing plasma ceramide accumulation (Rico et al., 2015a, 2017b), and ceramide has been proposed to mediate nonalcoholic FLD in nonruminants (Pagadala et al., 2012; Kasumov et al., 2015). Interestingly, PUFA may lower ceramide synthesis (Blachnio-Zabielska et al., 2010; Jin et al., 2018). In support, Duckett et al. (2019) demonstrated that the dietary supplementation of insulin-sensitizing palmitoleic acid decreased circulating C24:0- and C24: 1-ceramide concentrations in juvenile lambs, relative to no-lipid or $\alpha$-linolenic acid supplementation.

Although we have shown palmitic acid to be an inducer of ceramide synthesis in dairy cows, an important consideration is that dietary palmitic acid supplementation does not always increase milk yield in cows (Loften et al., 2014; de Souza et al., 2016). One possibility is that ceramide and localized insulin sensitivity were not modified in studies that did not report a change in milk yield with palm feeding. In addition, other SFA besides palmitic acid may increase ceramide synthesis via their incorporation by CerS (Figure 1); therefore, it may prove difficult to observe an effect on milk yield in studies evaluating palmitic acid feeding versus stearic acid. The functionality of stearoyl-CoA desaturase that transforms palmitic and stearic acids to their monounsaturated forms, and the effects of dietary nonlipid nutrients (e.g., starch) on ceramide synthesis deserve consideration within the context of changes in milk yield. Stage of lactation, changes in intake, body condition status, the complete lipolytic and dietary FA profile, and production level of the cow may also be influential factors.

\section{Ceramide Inhibits Adipocyte Insulin Signaling}

Ceramide may inhibit insulin signaling in dairy cows by downregulating AKT activation and GLUT4 translocation to the plasma membrane (Rico et al., 2018a). In primary bovine adipocytes, we evaluated the ability of ceramide to modulate AKT phosphorylation status (i.e., activation) and insulin-stimulated 2DOG uptake. First, we demonstrated that the inhibition of SPT and de novo ceramide synthesis by myriocin decreased intracellular ceramide and GlcCer concentrations. Additionally, the ceramide-lowering ability of myriocin developed with elevations in Ser-473 phosphorylation of AKT and 2DOG uptake in the presence of insulin. Second, primary bovine adipocytes were cultured with exogenous C2:0-ceramide, which is a hydrophilic ceramide that can freely pass through the plasma membrane. In this experiment, C2:0-ceramide impaired AKT phosphorylation and insulin-stimulated 2DOG uptake. Of importance, these findings were observed in differentiated bovine adipocytes cultured in nutrient excess. Upon reflection, the ability of palmitic acid feeding to increase ceramide supply and elevate circulating FA following a glucose challenge in mid-lactation cows may involve similar mechanisms. Indeed, the ability of ceramide to inhibit insulin action and promote lipolysis has been observed in nonruminants (Summers et al., 1998; Mei et al., 2002).

Although reductions in insulin sensitivity may contribute to lipolysis in the dairy cow (Pires et al., 2007), it is uncertain whether ceramide inhibits insulinstimulated AKT phosphorylation in adipose tissue of the early-lactation cow experiencing catabolism. It is expected that adipocyte FA oxidation increases with postpartum lipolysis; therefore, FA substrate for localized ceramide synthesis may be limiting. When FA release exceeds oxidative capacity of the adipocyte, then FA may be used to generate ceramide and inhibit insulin signaling in an autocrine manner. We also consider the possibility that ceramide does not inhibit the adipose tissue insulin signaling cascade immediately 
postpartum but rather serves as a repository of substrate (i.e., FA) for hepatic de novo ceramide synthesis. Based on work by Boon et al. (2013), hepatic-derived lipoprotein ceramide may antagonize AKT activation in skeletal muscle or promote macrophage inflammation. Because lipolytic-derived FA may be used to stimulate de novo ceramide synthesis in bovine skeletal muscle, intracellular ceramide may also inhibit insulin signaling in skeletal muscle. Although these outcomes are often observed in obese and insulin-resistant nonruminants experiencing myocellular lipid deposition (Corcoran et al., 2007), we do recognize the ability of diacylglycerol to also reduce insulin-stimulated glucose uptake via PKC-dependent mechanisms. In the dairy cow, the ability of ceramide or diacylglycerol to inhibit insulin signaling in skeletal muscle or myotubes has not been studied and requires further investigation.

\section{Summary}

A summary of established and potential mechanisms in the transition dairy cow is provided in Figure 6 . First, the magnitude of hepatic de novo ceramide synthesis is contingent on the state of energy balance, dietary- or lipolytic-derived FA supply, and the mitochondrial capacity to oxidize FA in liver. Periparturient cows with greater prepartum body fat reserves that mobilize more FA or those fed palmitic acid will experience greater elevations in de novo ceramide synthesis. Hepatic ceramides that are responsive to increased FA supply include C20:0- to C26:0-linked ceramides as well as C16:0-, C22:0-, and C24:0-GlcCer. It is likely that hepatic elongase, CerS, and glucosylceramide synthase play a critical role in regulating the production of ceramides. Once synthesized, ceramides are packaged within VLDL for secretion. Transition cows that experience inflammation may also experience activation of secretory A-SMase to transform LDL sphingomyelin into ceramide. Macrophage inflammation or palmitic acid (diet- or lipolytic-derived) may induce intracellular de novo ceramide synthesis in bovine adipose and skeletal muscle tissues. These ceramides may include C16:0- and C24:0-ceramide. Collectively, extracellular lipoprotein or intracellular ceramide may inhibit adipose and skeletal muscle insulin sensitivity via AKTdependent mechanisms to reduce glucose uptake. In adipose, ceramide-mediated insulin antagonism may also accelerate adipose tissue lipolysis. One outcome is the partitioning of glucose and FA toward milk and milk fat production, respectively. Another is the acceleration of hepatic FA uptake, which may predispose the transition cow to developing FLD. The ability of ceramide to partition nutrients may influence lactation and health.

\section{FUTURE DIRECTIONS}

\section{Does Ceramide Influence AKT Activation in the Bovine Mammary Gland?}

The serine/threonine kinase AKT has 2 major roles in mammary epithelial cells. First, the PI3K/AKT signaling pathway inhibits programmed cell death (i.e., apoptosis) to promote survival (Kennedy et al., 1997; Schwertfeger et al., 2001). Specifically, AKT inactivates cell death effector proteins BAD and caspase-9, and increases the abundance of anti-apoptotic protein Bcl-2 (Pettus et al., 2002; Bratton et al., 2010). Second, AKT orchestrates developmental changes that allow mammary nutrient uptake and synthesis for milk production (Boxer et al., 2006). Activation of AKT regulates the expression of the lipogenic transcription factor sterol regulatory element binding protein, as well as its proteolytic processing, to increase concentrations of cellular FA and glycerophospholipids (Porstmann et al., 2005; Zhang et al., 2018). Additionally, AKT-dependent activation of mammalian target of rapamycin (mTOR) stimulates protein translation via S6 kinase and eukaryotic elongation factor 2 (Hassan et al., 2013; Zhang et al., 2018). In the lactating goat, AKT expression is greatest in mid lactation followed by peak lactation, and lowest during the dry period and late lactation (Zhang et al., 2018). Unfortunately, our understanding of the role of sphingolipids in the mammary epithelial cell or their ability to regulate AKT-dependent cellular proliferation, survival, or lipid and protein synthesis is inadequately defined.

In alignment with milk sphingolipid levels (Bitman and Wood, 1990), the mammary expression of SPT1 and CerS2 is highest during peak lactation and declines gradually until dry-off (Bionaz and Loor, 2008). As described by Bionaz and Loor (2008), elevated ceramide synthesis may serve a regulatory role to maintain milk lipid synthesis (Worgall, 2007). Because ceramide is a potent inducer of apoptosis (Pettus et al., 2002), we also consider the possibilities that (1) the suppressed mammary expression of SPT1 and CerS2 during the dry period and early lactation ensures cellular proliferation, and (2) the heightened SPT1 and CerS2 expression of peak lactation initiates mammary gland regression through the process of apoptotic cell death. In support, unsaturated oleic acid activates AKT and induce cell proliferation in bovine mammary epithelial cells (Yonezawa et al., 2008), whereas saturated ceramide precursors palmitic and stearic acids induce apoptosis without inducing cellular proliferation (Hardy et al., 2000; Yonezawa et al., 2008). Recalling that ceramide activates PTEN (Hajduch et al., 2008), the overexpression of PTEN inhibits proliferation and differentiation, 
and milk yield while provoking apoptosis in mammary epithelial cells (Dupont et al., 2002; Wang et al., 2014). Upregulated apoptosis by ceramide may also explain observed decreases in mammary epithelial cells during chronic nutrient restriction in lactating cows (Dessauge et al., 2011), a signal that may be suppressed by the mammogenic and lactogenic roles of prolactin and somatotropin (Tucker, 1981; Capuco et al., 2001). Collectively, the role of ceramide in modulating mammary AKT function, apoptosis, and milk fat and protein synthesis represents a realm of dairy biology open for exploration.

\section{Are Ceramide and Inflammation Related in the Transition Cow?}

Chronic low-grade inflammation is a major promoter of obesity-associated insulin resistance (Hotamisligil, 2006; Osborn and Olefsky, 2012). In dairy cows, a high degree of inflammation is observed during the peripartum (Bertoni et al., 2008), which is exacerbated in overweight cows and those with FLD (Ohtsuka et al., 2001; O'Boyle et al., 2006). Two prominent mechanisms linking inflammation to insulin resistance include the activation of the toll-like receptors, which induce the transcription of inflammatory cytokines such as TNFo and IL-6 (Senn, 2006; Shi et al., 2006) as well as activation of sphingomyelinase (Peraldi et al., 1996). These inflammatory outcomes drive ceramide synthesis (Peraldi et al., 1996; Holland et al., 2011a). This is a potential concern if we consider that ceramide induces inflammation by activating nuclear factor- $\kappa \mathrm{B}$ signaling to promote the expression of $\mathrm{TNF} \alpha$, as demonstrated in RAW 264.7 macrophages (Boon et al., 2013). In the dairy cow, we need to determine whether inflammation promotes ceramide accrual and vice versa. The relative activities and contributions of the various sphingomyelinases (e.g., neutral and acid types in cell membranes and circulation) to postpartum ceramide accruals need to be evaluated within the context of TNF $\alpha$ status. We may need to ensure that approaches that enhance ceramide supply, as a potential means to restore glucose

\section{Small intestine $\quad$ Dietary sphingolipids degraded \\ - Palmitic acid absorbed to support de novo ceramide synthesis \\ Adipose \\ - Ceramide inhibits insulin-stimulated glucose uptake in par by inactivating AKT and decreased GLUT4 translocation \\ - Reduced insulin action by ceramide may promote lipolysis

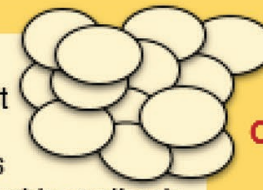 \\ - Lipolysis provides SFA substrate for hepatic de novo ceramide synthesis \\ - Dietary- or lipolytic-derived SFA may promote de novo ceramide synthesis \\ - Whether adipose secretes ceramide is uncertain \\ Skeletal muscle \\ - LDL or intracellular ceramide inhibits insulin-stimulated glucose uptake \\ - Dietary- or lipolytic-derived SFA provokes de novo ceramide synthesis

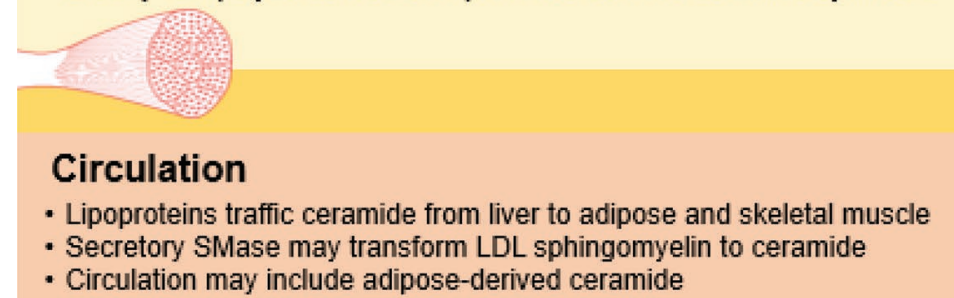 \\ - Circulation may include adipose-derived ceramide \\ Mammary gland \\ - Spared glucose and FA used for milk synthesis \\ - SPT and CerS2 expression follows lactation curve \\ - Direct role of ceramide on AKT activation, proliferation, and milk synthesis is uncertain \\ DE NOVO SYNTHESIS C16:0-CoA + serine ISPT 3-ketosphinganine Sphinganine SFA CerS1-6 Dihydroceramide Desaturase

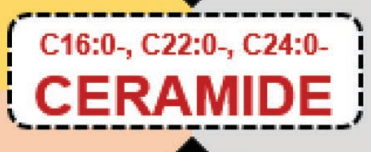 \\ SMase Sphingomyelin SPHINGOMYELIN HYDROLYSIS

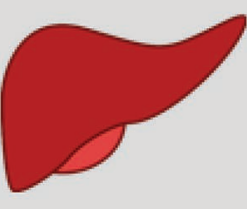 \\ Liver \\ - Risk for TAG deposition in early lactation \\ - Enhanced hepatic SFA uptake and limited FA oxidation increases de novo ceramide synthesis \\ - High CerS2 expression drives C22:0- and C24:0- ceramide synthesis \\ - Sphingomyelin hydrolysis occurs in presence of inflammation \\ - Ceramide incorporated into VLDL for secretion \\ Ceramide Biology}

Figure 6. Summary of ceramide biology. The diagram represents a summary of knowledge in mammals including dairy cattle, rodents, and humans. AKT = protein kinase B; CerS1-6 = ceramide synthases 1 to 6; GLUT4 = glucose transporter-4; LDL = low-density lipoprotein; SMase $=$ sphingomyelinase; SPT $=$ serine palmitoyltransferase; TAG = triacylglycerol; VLDL $=$ very-low-density lipoprotein; FA $=$ fatty acid. 
partitioning for milk production (e.g., palmitic acid feeding), do not inadvertently compromise health by provoking inflammation.

\section{Is the FGF21-Adiponectin-Ceramide Axis Uncoupled in the Early-Lactation Dairy Cow?}

Fibroblast growth factor 21 and adiponectin are 2 endocrine signals that promote energy expenditure (Steinberg and Kemp, 2007; Owen et al., 2014). As stated previously, the ability of FGF21 to improve glucose homeostasis during obesity involves the stimulation of adiponectin secretion (Holland et al., 2013). In diet-induced obese mice, the insulin-sensitizing effects of FGF21 are likely due to the ability of adiponectin to decrease ceramide accumulation (Holland et al., 2011b, 2013). This was not observed in ad libitum-fed nonpregnant, nonlactating dairy cows intravenously infused a TAG emulsion (Caixeta et al., 2017; Krumm et al., 2017; Rico et al., 2018c). In the early-lactation dairy cow experiencing negative energy balance, circulating FGF21 concentrations are high, whereas adiponectin levels are low (Schoenberg et al., 2011; Giesy et al., 2012). We postulate that suppressed adiponectin secretion during early lactation may contribute to ceramide accrual. Such findings would suggest that FGF21 does not modulate ceramide supply or improve insulin action in early-lactation cows because of unresponsive adiponectin secretion and upregulated ceramide synthesis.

\section{Are Ceramides Predictors of Postpartum Metabolic Disease?}

Common peripartal disorders such as FLD, ketosis, retained placenta, and displaced abomasum are associated with exacerbated negative energy balance and uncontrolled lipolysis, which are likely related to the severity of insulin antagonism (Herdt, 1988; Bobe et al., 2004; Roche et al., 2009). Consequently, circulating free $\mathrm{FA}$ and $\mathrm{BHB}$ concentrations are elevated in Holstein cows that develop peripartal diseases. However, the ability of these metabolites to predict for periparturient diseases and reproductive or lactation success may not be optimal. For example, Ospina et al. (2010) reported a low ability of prepartum serum free FA concentrations to predict postpartum displaced abomasum (sensitivity $=0.57$, specificity $=0.62$ for a serum free FA threshold of $0.27 \mathrm{mEq} / \mathrm{L}$ ). The power to predict clinical ketosis and metritis was even lower. Although the predictive power of both free FA and BHB improved when cows were sampled postpartum (i.e., higher sensitivity and specificity), its prognostic usefulness is obviously limited to a very small time window before the manifestation of disease. Although other studies have explored the use of different lipid biomarkers, including sphingomyelins, for the prediction of peripartal diseases (Hailemariam et al., 2014), limitations in sample size preclude extrapolation and generalization. Importantly, the efficacy of ceramides as predictors for disease, relative to free FA and BHB, has not been studied in dairy cows. This new focus is justified because ceramide has emerged as a novel biomarker for FLD, T2DM, and cardiovascular disease in humans (Laaksonen et al., 2016; Alonso et al., 2017; Hilvo et al., 2018). Although cow-side or laboratory ceramide monitoring may not become a reality, the identification of ceramide as a strong predictor for disease would likely trigger the development of nutritional or pharmacological therapies that modulate ceramide synthesis as a preventive measure to enhance insulin sensitivity, control lipolysis, and support health and longevity.

\section{Does Ceramide Mediate Somatotropin Action in Dairy Cattle?}

A key endocrine hormone and homeorhetic control of lactation is somatotropin (Bauman and Currie, 1980; Bell and Bauman, 1997). Circulating somatotropin levels are greatest during the copious milk production of early lactation (Koprowski and Tucker, 1973; Rhoads et al., 2004; Carcangiu et al., 2017). Somatotropin enhances basal and epinephrine-stimulated rates of lipolysis by inhibiting the antilipolytic actions of adenosine (Sechen et al., 1990; Lanna et al., 1995; Lanna and Bauman, 1999). The corresponding elevation in circulating free FA develops with the inactivation of skeletal muscle insulin signaling downstream of insulin receptor binding and the reduction in peripheral glucose disposal (Vernon et al., 1990; Wilson et al., 1996; Møller and Jørgensen, 2009). In detail, the ability of somatotropin to inhibit muscle glucose utilization likely involves the inactivation of IRS1, PI3K, and AKT to downregulate the translocation of GLUT4 to the plasma membrane (Rizza et al., 1982; Balage et al., 1997; Thirone et al., 1997). Importantly, these earlylactation outcomes develop with the uncoupling of the somatotropic axis during a catabolic state of negative energy balance (Bauman and Currie, 1980; Gluckman et al., 1987; Rhoads et al., 2004). Specifically, lactation initiates with a decrease in the release of the insulinsensitizer insulin-like growth factor-I from the liver. Because the ability of somatotropin to promote lipolysis would provide substrate for de novo ceramide synthesis, we hypothesize that somatotropin downregulates peripheral insulin signaling via ceramide-dependent mechanisms in a coordinated adipose-liver-muscle axis. Such a mechanism would link adipose energy reserve 
status with the magnitude of skeletal muscle insulin antagonism via the liver. Dietary therapies that decrease ceramide production could be developed as a means to improve insulin sensitivity during early lactation for optimum health. Alternatively, dietary approaches that increase ceramide synthesis could be used to enhance milk production efficiency later in lactation.

\section{CONCLUSIONS}

The discussion of lipolysis and nutrient partitioning within the context of lactation now includes a new chapter focused on ceramide. Although our comprehension of sphingolipid biology in the dairy cow was previously limited, scientific breakthroughs support the continued investigation of ceramide. The presumed ability of ceramide to regulate glucose utilization by modulating insulin signaling has major implications for maintaining postpartum health and milk production in dairy cattle. Additionally, the ability to utilize nutrition to modulate ceramide synthesis is a promising approach to control lipolysis, energy partitioning, and milk production in ruminants. The interplay between ceramide with regard to inflammation and endocrine function is also exciting to consider. Because of the growing accessibility of lipidomics technologies that can measure sphingolipids, we should expect the study of sphingolipid biology in the dairy cow to continue. In doing so, discoveries will continue to emerge that may challenge our understanding of bovine lipid biology, metabolic disease, and lactation.

\section{ACKNOWLEDGMENTS}

The research described was performed with major support from the Agriculture and Food Research Initiative Competitive Grants 2014-67016-21611 and 201667015-24582 from the US Department of Agriculture (USDA) National Institute of Food and Agriculture (Washington, DC), the USDA Northeast Sustainable Agriculture Research and Education Program (GNE13067), and Hatch Project WVA00661. The authors also express appreciation to F. Brad Hillgartner (West Virginia University, Morgantown) for impactful mentorship and intellectual insight.

\section{REFERENCES}

Adachi, R., Y. Asano, K. Ogawa, M. Oonishi, Y. Tanaka, and T. Kawamoto. 2018. Pharmacological characterization of synthetic serine palmitoyltransferase inhibitors by biochemical and cellular analyses. Biochem. Biophys. Res. Commun. 497:1171-1176.

Adams, J. M., T. Pratipanawatr, R. Berria, E. Wang, R. A. DeFronzo, M. C. Sullards, and L. J. Mandarino. 2004. Ceramide content is increased in skeletal muscle from obese insulin-resistant humans. Diabetes 53:25-31.
Alonso, C., D. Fernández-Ramos, M. Varela-Rey, I. Martínez-Arranz, N. Navasa, S. M. Van Liempd, J. L. L. Trueba, R. Mayo, C. P. Ilisso, and V. G. de Juan. 2017. Metabolomic identification of subtypes of nonalcoholic steatohepatitis. Gastroenterology 152:14491461.e7.

Amati, F., J. J. Dubé, E. Alvarez-Carnero, M. M. Edreira, P. Chomentowski, P. M. Coen, G. E. Switzer, P. E. Bickel, M. Stefanovic-Racic, F. G. S. Toledo, and B. H. Goodpaster. 2011. Skeletal muscle triglycerides, diacylglycerols, and ceramides in insulin resistance. Another paradox in endurance-trained athletes? Diabetes 60:2588-2597.

Balage, M., J. F. Hocquette, B. Graulet, P. Ferre, and J. Grizard. 1997. Skeletal muscle glucose transporter (GLUT-4) protein is decreased in lactating goats. Anim. Sci. 65:257-265.

Ballou, L. R., S. J. Laulederkind, E. F. Rosloniec, and R. Raghow. 1996. Ceramide signaling and the immune response. Biochim. Biophys. Acta 1301:273-287.

Bartke, N., and Y. A. Hannun. 2009. Bioactive sphingolipids: Metabolism and function. J. Lipid Res. 50:S91-S96.

Bauman, D. E., and W. B. Currie. 1980. Partitioning of nutrients during pregnancy and lactation: A review of mechanisms involving homeostasis and homeorhesis. J. Dairy Sci. 63:1514-1529.

Baumgard, L. H., R. Collier, and D. Bauman. 2017. A 100-Year Review: Regulation of nutrient partitioning to support lactation. J. Dairy Sci. 100:10353-10366.

Bell, A. W., and D. E. Bauman. 1997. Adaptations of glucose metabolism during pregnancy and lactation. J. Mammary Gland Biol. Neoplasia 2:265-278.

Bell, J. A., M. A. Reed, L. A. Consitt, O. J. Martin, K. R. Haynie, M. W. Hulver, D. M. Muoio, and G. L. Dohm. 2010. Lipid partitioning, incomplete fatty acid oxidation, and insulin signal transduction in primary human muscle cells: Effects of severe obesity, fatty acid incubation, and fatty acid translocase/CD36 overexpression. J. Clin. Endocrinol. Metab. 95:3400-3410.

Bertoni, G., E. Trevisi, X. Han, and M. Bionaz. 2008. Effects of inflammatory conditions on liver activity in puerperium period and consequences for performance in dairy cows. J. Dairy Sci. 91:33003310 .

Bionaz, M., and J. J. Loor. 2008. Gene networks driving bovine milk fat synthesis during the lactation cycle. BMC Genomics 9:366.

Bitman, J., and D. L. Wood. 1990. Changes in milk fat phospholipids during lactation. J. Dairy Sci. 73:1208-1216.

Blachnio-Zabielska, A., M. Baranowski, P. Zabielski, and J. Gorski. 2010. Effect of high fat diet enriched with unsaturated and diet rich in saturated fatty acids on sphingolipid metabolism in rat skeletal muscle. J. Cell. Physiol. 225:786-791.

Blouin, C. M., C. Prado, K. K. Takane, F. Lasnier, A. Garcia-Ocana, P. Ferre, I. Dugail, and E. Hajduch. 2010. Plasma membrane subdomain compartmentalization contributes to distinct mechanisms of ceramide action on insulin signaling. Diabetes 59:600-610.

Bobe, G., J. Young, and D. Beitz. 2004. Invited review: Pathology, etiology, prevention, and treatment of fatty liver in dairy cows. J. Dairy Sci. 87:3105-3124.

Boon, J., A. J. Hoy, R. Stark, R. D. Brown, R. C. Meex, D. C. Henstridge, S. Schenk, P. J. Meikle, J. F. Horowitz, B. A. Kingwell, C. R. Bruce, and M. J. Watt. 2013. Ceramides contained in LDL are elevated in type 2 diabetes and promote inflammation and skeletal muscle insulin resistance. Diabetes 62:401-410.

Borén, J., M. R. Taskinen, S. O. Olofsson, and M. Levin. 2013. Ectopic lipid storage and insulin resistance: A harmful relationship. J. Intern. Med. 274:25-40.

Borodzicz, S., K. Czarzasta, M. Kuch, and A. Cudnoch-Jedrzejewska. 2015. Sphingolipids in cardiovascular diseases and metabolic disorders. Lipids Health Dis. 14:55.

Borst, S. E. 2004. The role of TNF- $\alpha$ in insulin resistance. Endocrine $23: 177-182$

Bouhours, J.-F., and D. Bouhours. 1981. Ceramide structure of sphingomyelin from human milk fat globule membrane. Lipids 16:726731.

Boxer, R. B., D. B. Stairs, K. D. Dugan, K. L. Notarfrancesco, C. P. Portocarrero, B. A. Keister, G. K. Belka, H. Cho, J. C. Rathmell, 
and C. B. Thompson. 2006. Isoform-specific requirement for Akt1 in the developmental regulation of cellular metabolism during lactation. Cell Metab. 4:475-490.

Bratton, M. R., B. N. Duong, S. Elliott, C. B. Weldon, B. S. Beckman, J. A. McLachlan, and M. E. Burow. 2010. Regulation of $\mathrm{ER} \alpha$-mediated transcription of Bcl-2 by PI3K-AKT crosstalk: Implications for breast cancer cell survival. Int. J. Oncol. 37:541-550.

Brozinick, J. T., E. Hawkins, H. Hoang Bui, M. S. Kuo, B. Tan, P. Kievit, and K. Grove. 2013. Plasma sphingolipids are biomarkers of metabolic syndrome in non-human primates maintained on a Western-style diet. Int. J. Obes. (Lond.) 37:1064-1070.

Bruce, C. R., S. Risis, J. R. Babb, C. Yang, R. S. Lee-Young, D. C. Henstridge, and M. A. Febbraio. 2013. The sphingosine-1-phosphate analog FTY720 reduces muscle ceramide content and improves glucose tolerance in high fat-fed male mice. Endocrinology 154:65-76.

Caixeta, L. S., S. L. Giesy, C. S. Krumm, J. W. Perfield, A. Butterfield, K. M. Schoenberg, D. C. Beitz, and Y. R. Boisclair. 2017. Effect of circulating glucagon and free fatty acids on hepatic FGF21 production in dairy cows. Am. J. Physiol. Regul. Integr. Comp. Physiol. 313:R526-R534.

Capuco, A. V., D. Wood, R. Baldwin, K. Mcleod, and M. Paape. 2001. Mammary cell number, proliferation, and apoptosis during a bovine lactation: relation to milk production and effect of bST. J. Dairy Sci. 84:2177-2187.

Caputo, T., F. Gilardi, and B. Desvergne. 2017. From chronic overnutrition to metaflammation and insulin resistance: Adipose tissue and liver contributions. FEBS Lett. 591:3061-3088.

Carcangiu, V., C. Giannetto, S. Luridiana, F. Fazio, M. Mura, A. Parmeggiani, and G. Piccione. 2017. Lactation influences the serum level of leptin and growth hormone during the daily bathyphase in ewes. Biol. Rhythm Res. 48:35-41.

Chavez, J. A., T. A. Knotts, L. P. Wang, G. B. Li, R. T. Dobrowsky, G. L. Florant, and S. A. Summers. 2003. A role for ceramide, but not diacylglycerol, in the antagonism of insulin signal transduction by saturated fatty acids. J. Biol. Chem. 278:10297-10303.

Chavez, J. A., and S. A. Summers. 2003. Characterizing the effects of saturated fatty acids on insulin signaling and ceramide and diacylglycerol accumulation in 3T3-L1 adipocytes and C2C12 myotubes. Arch. Biochem. Biophys. 419:101-109.

Chavez, J. A., and S. A. Summers. 2012. A ceramide-centric view of insulin resistance. Cell Metab. 15:585-594.

Cheng, Y., Å. Nilsson, E. Tömquist, and R.-D. Duan. 2002. Purification, characterization, and expression of rat intestinal alkaline sphingomyelinase. J. Lipid Res. 43:316-324.

Chilliard, Y., A. Ferlay, R. M. Mansbridge, and M. Doreau. 2000. Ruminant milk fat plasticity: Nutritional control of saturated, polyunsaturated, trans and conjugated fatty acids. Ann. Zootech. 49:181-205.

Christie, W., R. Noble, and G. Davies. 1987. Phospholipids in milk and dairy products. Int. J. Dairy Technol. 40:10-12.

Corcoran, M. P., S. Lamon-Fava, and R. A. Fielding. 2007. Skeletal muscle lipid deposition and insulin resistance: effect of dietary fatty acids and exercise. Am. J. Clin. Nutr. 85:662-677.

Cowart, L. A. 2009. Sphingolipids: Players in the pathology of metabolic disease. Trends Endocrinol. Metab. 20:34-42.

Davis, A. N., J. L. Clegg, C. A. Perry, and J. W. McFadden. 2017a. Nutrient restriction increases circulating and hepatic ceramide in dairy cows displaying impaired insulin tolerance. Lipids 52:771780 .

Davis, A. N., Z. C. Phipps, Q. Zeng, J. de Souza, J. E. Rico, A. L. Lock, and J. W. McFadden. 2017b. Palmitic acid feeding increases plasma ceramide concentrations in Holstein dairy cows during early lactation. J. Dairy Sci. 100(E-Suppl. 2):101. (Abstr.)

De Koster, J. D., and G. Opsomer. 2013. Insulin resistance in dairy cows. Vet. Clin. North Am. Food Anim. Pract. 29:299-322.

de Souza, J., and A. L. Lock. 2018. Long-term palmitic acid supplementation interacts with parity in lactating dairy cows: Production responses, nutrient digestibility, and energy partitioning. J. Dairy Sci. 101:3044-3056. de Souza, J., C. Preseault, and A. Lock. 2018. Altering the ratio of dietary palmitic, stearic, and oleic acids in diets with or without whole cottonseed affects nutrient digestibility, energy partitioning, and production responses of dairy cows. J. Dairy Sci. 101:172-185.

de Souza, J., C. Strieder-Barboza, G. Contreras, and A. Lock. 2019. Effects of timing of palmitic acid supplementation during early lactation on nutrient digestibility, energy balance, and metabolism of dairy cows. J. Dairy Sci. 102:274-287.

de Souza, J., R. Tempelman, M. Allen, and A. Lock. 2016. Production response, nutrient digestibility, and energy partitioning of postpeak dairy cows when palmitic acid- enriched supplements are included in diets: A meta-analysis and meta-regression. J. Anim. Sci. 94(Suppl. 5):632. (Abstr.)

DeFronzo, R. A., and D. Tripathy. 2009. Skeletal muscle insulin resistance is the primary defect in type 2 diabetes. Diabetes Care 32:S157-S163.

Dessauge, F., V. Lollivier, B. Ponchon, R. Bruckmaier, L. Finot, S. Wiart, E. Cutullic, C. Disenhaus, S. Barbey, and M. Boutinaud. 2011. Effects of nutrient restriction on mammary cell turnover and mammary gland remodeling in lactating dairy cows. J. Dairy Sci. 94:4623-4635.

Douglas, G. N., J. Rehage, A. D. Beaulieu, A. O. Bahaa, and J. K. Drackley. 2007. Prepartum nutrition alters fatty acid composition in plasma, adipose tissue, and liver lipids of periparturient dairy cows. J. Dairy Sci. 90:2941-2959.

Duan, R.-D. 2006. Alkaline sphingomyelinase: An old enzyme with novel implications. Biochim. Biophys. Acta 1761:281-291.

Duckett, S. K., I. Furusho-Garcia, J. E. Rico, and J. W. McFadden. 2019. Flaxseed oil or n-7 fatty acid-enhanced fish oil supplementation alters fatty acid composition, plasma insulin and serum ceramide concentrations, and gene expression in lambs. Lipids 54:389-399. https://doi.org/10.1002/lipd.12156.

Duffield, T. F., K. Lissemore, B. McBride, and K. Leslie. 2009. Impact of hyperketonemia in early lactation dairy cows on health and production. J. Dairy Sci. 92:571-580.

Dupont, J., J. P. Renou, M. Shani, L. Hennighausen, and D. LeRoith. 2002. PTEN overexpression suppresses proliferation and differentiation and enhances apoptosis of the mouse mammary epithelium. J. Clin. Invest. 110:815-825.

Erion, D. M., and G. I. Shulman. 2010. Diacylglycerol-mediated insulin resistance. Nat. Med. 16:400-402.

Genin, M. J., I. C. Gonzalez Valcarcel, W. G. Holloway, J. Lamar, M. Mosior, E. Hawkins, T. Estridge, J. Weidner, T. Seng, and D. Yurek. 2016. Imidazopyridine and pyrazolopiperidine derivatives as novel inhibitors of serine palmitoyl transferase. J. Med. Chem. 59:5904-5910.

Ghosh, N., R. Sabbadini, and S. Chatterjee. 1998. Identification, partial purification, and localization of a neutral sphingomyelinase in rabbit skeletal muscle: Neutral sphingomyelinase in skeletal muscle. Mol. Cell. Biochem. 189:161-168.

Giesy, S. L., B. Yoon, W. B. Currie, J. W. Kim, and Y. R. Boisclair. 2012. Adiponectin deficit during the precarious glucose economy of early lactation in dairy cows. Endocrinology 153:5834-5844.

Gilchrist, D. G. 1997. Mycotoxins reveal connections between plants and animals in apoptosis and ceramide signaling. Cell Death Differ. 4:689-698.

Gluckman, P. D., B. H. Breier, and S. R. Davis. 1987. Physiology of the somatotropic axis with particular reference to the ruminant. J. Dairy Sci. 70:442-466.

Goñi, F. M., and A. Alonso. 2002. Sphingomyelinases: Enzymology and membrane activity. FEBS Lett. 531:38-46.

Hage Hassan, R., A. C. P. de Sousa, R. Mahfouz, I. Hainault, A. Blachnio-Zabielska, O. Bourron, F. Koskas, J. Górski, P. Ferré, and F. Foufelle. 2016. Sustained action of ceramide on the insulin signaling pathway in muscle cells: Implication of the double-stranded RNA-activated protein kinase. J. Biol. Chem. 291:3019-3029.

Hailemariam, D., R. Mandal, F. Saleem, S. Dunn, D. Wishart, and B. Ametaj. 2014. Identification of predictive biomarkers of disease state in transition dairy cows. J. Dairy Sci. 97:2680-2693.

Hajduch, E., S. Turban, X. Le Liepvre, S. Le Lay, C. Lipina, N. Dimopoulos, I. Dugail, and H. S. Hundal. 2008. Targeting of PKC $\zeta$ 
and PKB to caveolin-enriched microdomains represents a crucial step underpinning the disruption in PKB-directed signaling by ceramide. Biochem. J. 410:369-379.

Hammad, S. M., J. S. Pierce, F. Soodavar, K. J. Smith, M. M. Al Gadban, B. Rembiesa, R. L. Klein, Y. A. Hannun, J. Bielawski, and A. Bielawska. 2010. Blood sphingolipidomics in healthy humans: Impact of sample collection methodology. J. Lipid Res. 51:3074-3087.

Hannun, Y. A., and L. M. Obeid. 2008. Principles of bioactive lipid signaling: Lessons from sphingolipids. Nat. Rev. Mol. Cell Biol. 9:139-150.

Hardy, S., Y. Langelier, and M. Prentki. 2000. Oleate activates phosphatidylinositol 3-kinase and promotes proliferation and reduces apoptosis of MDA-MB-231 breast cancer cells, whereas palmitate has opposite effects. Cancer Res. 60:6353-6358.

Hassan, B., A. Akcakanat, A. M. Holder, and F. Meric-Bernstam. 2013. Targeting the PI3-kinase/Akt/mTOR signaling pathway. Surg. Oncol. Clin. N. Am. 22:641-664.

Haus, J. M., S. R. Kashyap, T. Kasumov, R. Zhang, K. R. Kelly, R. A. DeFronzo, and J. P. Kirwan. 2009. Plasma ceramides are elevated in obese subjects with type 2 diabetes and correlate with the severity of insulin resistance. Diabetes 58:337-343.

Heid, H. W., and T. W. Keenan. 2005. Intracellular origin and secretion of milk fat globules. Eur. J. Cell Biol. 84:245-258.

Herdt, T. H. 1988. Fatty liver in dairy cows. Vet. Clin. North Am. Food Anim. Pract. 4:269-287.

Higuchi, H., M. Nakamura, A. Kuwano, M. Kasamatsu, and H. Nagahata. 2005. Quantities and types of ceramides and their relationships to physical properties of the horn covering the claws of clinically normal cows and cows with subclinical laminitis. Can. J. Vet. Res. 69:155.

Hilvo, M., T. Salonurmi, A. S. Havulinna, D. Kauhanen, E. R. Pedersen, G. S. Tell, K. Meyer, A.-M. Teeriniemi, T. Laatikainen, and P. Jousilahti. 2018. Ceramide stearic to palmitic acid ratio predicts incident diabetes. Diabetologia 61:1424-1434.

Hofmann, K., S. Tomiuk, G. Wolff, and W. Stoffel. 2000. Cloning and characterization of the mammalian brain-specific, $\mathrm{Mg} 2+-$ dependent neutral sphingomyelinase. Proc. Natl. Acad. Sci. USA 97:5895-5900.

Holland, W. L., A. C. Adams, J. T. Brozinick, H. H. Bui, Y. Miyauchi, C. M. Kusminski, S. M. Bauer, M. Wade, E. Singhal, and C. C. Cheng. 2013. An FGF21-adiponectin-ceramide axis controls energy expenditure and insulin action in mice. Cell Metab. 17:790-797.

Holland, W. L., B. T. Bikman, L.-P. Wang, G. Yuguang, K. M. Sargent, S. Bulchand, T. A. Knotts, G. Shui, D. J. Clegg, and M. R. Wenk. 2011a. Lipid-induced insulin resistance mediated by the proinflammatory receptor TLR4 requires saturated fatty acid-induced ceramide biosynthesis in mice. J. Clin. Invest. 121:18581870 .

Holland, W. L., J. T. Brozinick, L.-P. Wang, E. D. Hawkins, K. M. Sargent, Y. Liu, K. Narra, K. L. Hoehn, T. A. Knotts, A. Siesky, D. H. Nelson, S. K. Karathanasis, G. K. Fontenot, M. J. Birnbaum, and S. A. Summers. 2007. Inhibition of ceramide synthesis ameliorates glucocorticoid-, saturated-fat-, and obesity-induced insulin resistance. Cell Metab. 5:167-179.

Holland, W. L., R. A. Miller, Z. V. Wang, K. Sun, B. M. Barth, H. H. Bui, K. E. Davis, B. T. Bikman, N. Halberg, and J. M. Rutkowski. 2011b. Receptor-mediated activation of ceramidase activity initiates the pleiotropic actions of adiponectin. Nat. Med. 17:55-63.

Holtenius, P., and K. Holtenius. 2007. A model to estimate insulin sensitivity in dairy cows. Acta Vet. Scand. 49:29.

Hotamisligil, G. S. 2006. Inflammation and metabolic disorders. Nature 444:860-867.

Iqbal, J., M. T. Walsh, S. M. Hammad, M. Cuchel, P. Tarugi, R. A. Hegele, N. O. Davidson, D. J. Rader, R. L. Klein, and M. M. Hussain. 2015. Microsomal triglyceride transfer protein transfers and determines plasma concentrations of ceramide and sphingomyelin but not glycosylceramide. J. Biol. Chem. 290:25863-25875.

Itani, S. I., N. B. Ruderman, F. Schmieder, and G. Boden. 2002. Lipid-induced insulin resistance in human muscle is associated with changes in diacylglycerol, protein kinase $\mathrm{C}$, and I $\mathrm{I} \mathrm{B}-\alpha$. Diabetes 51:2005-2011.
Jensen, R. G. 2002. The composition of bovine milk lipids: January 1995 to December 2000. J. Dairy Sci. 85:295-350.

Jin, J., Z. Lu, Y. Li, L. A. Cowart, M. F. Lopes-Virella, and Y. Huang. 2018. Docosahexaenoic acid antagonizes the boosting effect of palmitic acid on LPS inflammatory signaling by inhibiting gene transcription and ceramide synthesis. PLoS One 13:e0193343.

Jin, J., X. Zhang, Z. Lu, D. M. Perry, Y. Li, S. B. Russo, L. A. Cowart, Y. A. Hannun, and Y. Huang. 2013. Acid sphingomyelinase plays a key role in palmitic acid-amplified inflammatory signaling triggered by lipopolysaccharide at low concentrations in macrophages. Am. J. Physiol. Endocrinol. Metab. 305:E853-E867.

Kasumov, T., L. Li, M. Li, K. Gulshan, J. P. Kirwan, X. Liu, S. Previs, B. Willard, J. D. Smith, and A. McCullough. 2015. Ceramide as a mediator of non-alcoholic fatty liver disease and associated atherosclerosis. PLoS One 10:e0126910.

Kennedy, S. G., A. J. Wagner, S. D. Conzen, J. Jordan, A. Bellacosa P. N. Tsichlis, and N. Hay. 1997. The PI 3-kinase/Akt signaling pathway delivers an anti-apoptotic signal. Genes Dev. 11:701-713.

Kinnunen, P. K., and J. M. Holopainen. 2002. Sphingomyelinase activity of LDL: A link between atherosclerosis, ceramide, and apoptosis? Trends Cardiovasc. Med. 12:37-42.

Kolak, M., J. Westerbacka, V. R. Velagapudi, D. Wågsäter, L. Yetukuri, J. Makkonen, A. Rissanen, A.-M. Häkkinen, M. Lindell, and R. Bergholm. 2007. Adipose tissue inflammation and increased ceramide content characterize subjects with high liver fat content independent of obesity. Diabetes 56:1960-1968.

Konstantynowicz-Nowicka, K., E. Harasim, M. Baranowski, and A. Chabowski. 2015. New evidence for the role of ceramide in the development of hepatic insulin resistance. PLoS One 10:e0116858.

Koprowski, J. A., and H. A. Tucker. 1973. Bovine serum growth hormone, corticoids and insulin during lactation. Endocrinology 93:645-651.

Kornek, M., M. Lynch, S. H. Mehta, M. Lai, M. Exley, N. H. Afdhal, and D. Schuppan. 2012. Circulating microparticles as diseasespecific biomarkers of severity of inflammation in patients with hepatitis $\mathrm{C}$ or nonalcoholic steatohepatitis. Gastroenterology 143:448-458.

Koves, T. R., J. R. Ussher, R. C. Noland, D. Slentz, M. Mosedale, O. Ilkayeva, J. Bain, R. Stevens, J. R. Dyck, and C. B. Newgard. 2008. Mitochondrial overload and incomplete fatty acid oxidation contribute to skeletal muscle insulin resistance. Cell Metab. $7: 45-56$.

Kremer, G. J., W. Atzpodien, and E. Schnellbacher. 1975. Plasma glycosphingolipids in diabetics and normals. Klin. Wochenschr. 53:637-638.

Krumm, C. S., S. Giesy, L. Caixeta, W. Butler, H. Sauerwein, J. Kim, and Y. Boisclair. 2017. Effect of hormonal and energy-related factors on plasma adiponectin in transition dairy cows. J. Dairy Sci. 100:9418-9427.

Laaksonen, R., K. Ekroos, M. Sysi-Aho, M. Hilvo, T. Vihervaara, D. Kauhanen, M. Suoniemi, R. Hurme, W. März, and H. Scharnagl. 2016. Plasma ceramides predict cardiovascular death in patients with stable coronary artery disease and acute coronary syndromes beyond LDL-cholesterol. Eur. Heart J. 37:1967-1976.

Lanna, D. P., K. L. Houseknecht, D. M. Harris, and D. E. Bauman. 1995. Effect of somatotropin treatment on lipogenesis, lipolysis, and related cellular mechanisms in adipose tissue of lactating cows. J. Dairy Sci. 78:1703-1712.

Lanna, D. P. D., and D. E. Bauman. 1999. Effect of somatotropin, insulin, and glucocorticoid on lipolysis in chronic cultures of adipose tissue from lactating cows. J. Dairy Sci. 82:60-68.

Law, B. A., X. Liao, K. S. Moore, A. Southard, P. Roddy, R. Ji, Z. Szulc, A. Bielawska, P. C. Schulze, and L. A. Cowart. 2018. Lipotoxic very-long-chain ceramides cause mitochondrial dysfunction, oxidative stress, and cell death in cardiomyocytes. FASEB J. 32:1403-1416.

Levy, M., and A. H. Futerman. 2010. Mammalian ceramide synthases. IUBMB Life 62:347-356.

Lightle, S., R. Tosheva, A. Lee, J. Queen-Baker, B. Boyanovsky, S. Shedlofsky, and M. Nikolova-Karakashian. 2003. Elevation of ceramide in serum lipoproteins during acute phase response in hu- 
mans and mice: Role of serine-palmitoyl transferase. Arch. Biochem. Biophys. 419:120-128.

Lionetti, L., M. P. Mollica, A. Lombardi, G. Cavaliere, G. Gifuni, and A. Barletta. 2009. From chronic overnutrition to insulin resistance: The role of fat-storing capacity and inflammation. Nutr. Metab. Cardiovasc. Dis. 19:146-152.

Lock, A. L., K. J. Harvatine, J. K. Drackley, and D. E. Bauman. 2006. Concepts in fat and fatty acid digestion in ruminants. Pages 85-100 in Proc. Intermountain Nutr. Conf. Utah State University, Logan.

Loften, J. R., J. G. Linn, J. K. Drackley, T. C. Jenkins, C. G. Soderholm, and A. F. Kertz. 2014. Invited review: Palmitic and stearic acid metabolism in lactating dairy cows. J. Dairy Sci. 97:46614674.

Lopez, C., V. Briard-Bion, O. Menard, F. Rousseau, P. Pradel, and J.-M. Besle. 2008. Phospholipid, sphingolipid, and fatty acid compositions of the milk fat globule membrane are modified by diet. J. Agric. Food Chem. 56:5226-5236.

Lopez, X., A. B. Goldfine, W. L. Holland, R. Gordillo, and P. E. Scherer. 2013. Plasma ceramides are elevated in female children and adolescents with type 2 diabetes. J. Pediatr. Endocrinol. Metab. 26:995-998.

Maia, M. R., L. C. Chaudhary, C. S. Bestwick, A. J. Richardson, N. McKain, T. R. Larson, I. A. Graham, and R. J. Wallace. 2010. Toxicity of unsaturated fatty acids to the biohydrogenating ruminal bacterium, Butyrivibrio fibrisolvens. BMC Microbiol. 10:52.

Maia, M. R., L. C. Chaudhary, L. Figueres, and R. J. Wallace. 2007. Metabolism of polyunsaturated fatty acids and their toxicity to the microflora of the rumen. Antonie van Leeuwenhoek 91:303-314.

Mandon, E. C., I. Ehses, J. Rother, G. van Echten, and K. Sandhoff. 1992. Subcellular localization and membrane topology of serine palmitoyltransferase, 3-dehydrosphinganine reductase, and sphinganine N-acyltransferase in mouse liver. J. Biol. Chem. 267:1114411148.

Mann, S., F. A. L. Yepes, M. Duplessis, J. J. Wakshlag, T. R. Overton, B. P. Cummings, and D. V. Nydam. 2016. Dry period plane of energy: Effects on glucose tolerance in transition dairy cows. J. Dairy Sci. 99:701-717.

Marchesini, N., and Y. A. Hannun. 2004. Acid and neutral sphingomyelinases: Roles and mechanisms of regulation. Biochem. Cell Biol. 82:27-44.

Mathews, A. T., O. Famodu, M. Olfert, P. Murray, C. Cuff, M. Downes, N. Haughey, S. Colby, P. Chantler, I. Olfert, and J. W. McFadden. 2017. Efficacy of nutritional interventions to lower circulating ceramides in young adults: FRUVEDomic pilot study. Physiol. Rep. 5:e13329.

Mathews, A. T., J. E. Rico, N. T. Sprenkle, A. L. Lock, and J. W McFadden. 2016. Increasing palmitic acid intake enhances milk production and prevents glucose-stimulated fatty acid disappearance without modifying systemic glucose tolerance in mid-lactation dairy cows. J. Dairy Sci. 99:8802-8816.

Mathur, S., P. D. Constable, R. M. Eppley, A. L. Waggoner, M. E. Tumbleson, and W. M. Haschek. 2001. Fumonisin B1 is hepatotoxic and nephrotoxic in milk-fed calves. Toxicol. Sci. 60:385-396.

McFadden, J. W., J. E. Rico, S. J. Erb, and H. M. White. 2018. Inhibition of serine palmitoyltransferase prevents palmitic acid-induced ceramide synthesis in bovine primary hepatocytes. J. Dairy Sci. 101(E-Suppl. 2):105. (Abstr.)

Mei, J., L. S. Holst, T. R. Landström, C. Holm, D. Brindley, V. Manganiello, and E. Degerman. 2002. C2-ceramide influences the expression and insulin-mediated regulation of cyclic nucleotide phosphodiesterase 3B and lipolysis in 3T3-L1 adipocytes. Diabetes $51: 631-637$.

Merrill, A. H., S. Lingrell, E. Wang, M. Nikolova-Karakashian, T. R. Vales, and D. E. Vance. 1995. Sphingolipid biosynthesis de novo by rat hepatocytes in culture. Ceramide and sphingomyelin are associated with, but not required for, very low density lipoprotein secretion. J. Biol. Chem. 270:13834-13841.

Møller, N., and J. O. L. Jørgensen. 2009. Effects of growth hormone on glucose, lipid, and protein metabolism in human subjects. Endocr. Rev. 30:152-177.
Morrison, W. R., and J. Hay. 1970. Polar lipids in bovine milk II. Long-chain bases, normal and 2- hydroxy fatty acids, and isomeric cis and trans monoenoic fatty acids in the sphingolipids. Biochim. Biophys. Acta 202:460-467.

Mullen, T. D., Y. A. Hannun, and L. M. Obeid. 2012. Ceramide synthases at the center of sphingolipid metabolism and biology. Biochem. J. 441:789-802.

Neill, A. R., D. Grime, A. Snoswell, A. Northrop, D. Lindsay, and R. Dawson. 1979. The low availability of dietary choline for the nutrition of the sheep. Biochem. J. 180:559-565.

Nguyen, M. T., H. Satoh, S. Favelyukis, J. L. Babendure, T. Imamura, J. I. Sbodio, J. Zalevsky, B. I. Dahiyat, N.-W. Chi, and J. M. Olefsky. 2005. JNK and tumor necrosis factor- $\alpha$ mediate free fatty acid-induced insulin resistance in 3T3-L1 adipocytes. J. Biol. Chem. 280:35361-35371.

Nilsson, Å., and R.-D. Duan. 2006. Absorption and lipoprotein transport of sphingomyelin. J. Lipid Res. 47:154-171.

Norris, G. H., C. M. Porter, C. Jiang, C. L. Millar, and C. N. Blesso. 2017. Dietary sphingomyelin attenuates hepatic steatosis and adipose tissue inflammation in high-fat-diet-induced obese mice. J. Nutr. Biochem. 40:36-43.

O'Boyle, N., C. M. Corl, J. C. Gandy, and L. M. Sordillo. 2006. Relationship of body condition score and oxidant stress to tumor necrosis factor expression in dairy cattle. Vet. Immunol. Immunopathol. 113:297-304.

Ogretmen, B., and Y. A. Hannun. 2004. Biologically active sphingolipids in cancer pathogenesis and treatment. Nat. Rev. Cancer 4:604-616.

Ohno, Y., S. Suto, M. Yamanaka, Y. Mizutani, S. Mitsutake, Y. Igarashi, T. Sassa, and A. Kihara. 2010. ELOVL1 production of C24 acyl-CoAs is linked to C24 sphingolipid synthesis. Proc. Natl. Acad. Sci. USA 107:18439-18444.

Ohtsuka, H., M. Koiwa, A. Hatsugaya, K. Kudo, F. Hoshi, N. Itoh, H. Yokota, H. Okada, and S.-I. Kawamura. 2001. Relationship between serum TNF activity and insulin resistance in dairy cows affected with naturally occurring fatty liver. J. Vet. Med. Sci. 63:1021-1025.

Osborn, O., and J. M. Olefsky. 2012. The cellular and signaling networks linking the immune system and metabolism in disease. Nat. Med. 18:363-374.

Ospina, P. A., D. V. Nydam, T. Stokol, and T. R. Overton. 2010. Evaluation of nonesterified fatty acids and $\beta$-hydroxybutyrate in transition dairy cattle in the northeastern United States: Critical thresholds for prediction of clinical diseases. J. Dairy Sci. 93:546554

Owen, B. M., X. Ding, D. A. Morgan, K. C. Coate, A. L. Bookout, K. Rahmouni, S. A. Kliewer, and D. J. Mangelsdorf. 2014. FGF21 acts centrally to induce sympathetic nerve activity, energy expenditure, and weight loss. Cell Metab. 20:670-677.

Pagadala, M., T. Kasumov, A. J. McCullough, N. N. Zein, and J. P. Kirwan. 2012. Role of ceramides in nonalcoholic fatty liver disease. Trends Endocrinol. Metab. 23:365-371.

Peraldi, P., G. S. Hotamisligil, W. A. Buurman, M. F. White, and B. M. Spiegelman. 1996. Tumor necrosis factor (TNF)-alpha inhibits insulin signaling through stimulation of the p55 TNF receptor and activation of sphingomyelinase. J. Biol. Chem. 271:13018-13022.

Peraldi, P., and B. Spiegelman. 1998. TNF- $\alpha$ and insulin resistance: Summary and future prospects. Mol. Cell. Biochem. 182:169-175.

Petersen, M. C., and M. J. Jurczak. 2016. CrossTalk opposing view: Intramyocellular ceramide accumulation does not modulate insulin resistance. J. Physiol. 594:3171-3174.

Pettus, B. J., C. E. Chalfant, and Y. A. Hannun. 2002. Ceramide in apoptosis: An overview and current perspectives. Biochim. Biophys. Acta 1585:114-125.

Pewzner-Jung, Y., S. Ben-Dor, and A. H. Futerman. 2006. When do Lasses (longevity assurance genes) become CerS (ceramide synthases)? Insights into the regulation of ceramide synthesis. J. Biol. Chem. 281:25001-25005.

Pfeiffer, A., A. Böttcher, E. Orsó, M. Kapinsky, P. Nagy, A. Bodnár, I. Spreitzer, G. Liebisch, W. Drobnik, K. Gempel, M. Horn, S. Holmer, T. Hartung, G. Multhoff, G. Schütz, H. Schindler, A. J. 
Ulmer, H. Heine, F. Stelter, C. Schütt, G. Rothe, J. Szöllôsi, S. Damjanovich, and G. Schmitz. 2001. Lipopolysaccharide and ceramide docking to CD14 provokes ligand-specific receptor clustering in rafts. Eur. J. Immunol. 31:3153-3164.

Piantoni, P., A. Lock, and M. Allen. 2013. Palmitic acid increased yields of milk and milk fat and nutrient digestibility across production level of lactating cows. J. Dairy Sci. 96:7143-7154.

Pires, J. A., A. Souza, and R. Grummer. 2007. Induction of hyperlipidemia by intravenous infusion of tallow emulsion causes insulin resistance in Holstein cows. J. Dairy Sci. 90:2735-2744.

Porstmann, T., B. Griffiths, Y.-L. Chung, O. Delpuech, J. R. Griffiths, J. Downward, and A. Schulze. 2005. PKB/Akt induces transcription of enzymes involved in cholesterol and fatty acid biosynthesis via activation of SREBP. Oncogene 24:6465-6481.

Powell, D. J., E. Hajduch, G. Kular, and H. S. Hundal. 2003. Ceramide disables 3-phosphoinositide binding to the pleckstrin homology domain of protein kinase B (PKB)/Akt by a PKC -dependent mechanism. Mol. Cell. Biol. 23:7794-7808.

Raichur, S., S. T. Wang, P. W. Chan, Y. Li, J. Ching, B. Chaurasia, S. Dogra, M. K. Öhman, K. Takeda, S. Sugii, Y. Pewzner-Jung, A. H. Futerman, and S. A. Summers. 2014. CerS2 haploinsufficiency inhibits $\beta$-oxidation and confers susceptibility to diet-induced steatohepatitis and insulin resistance. Cell Metab. 20:687-695.

Rao, B. G., and M. W. Spence. 1976. Sphingomyelinase activity at $\mathrm{pH} 7.4$ in human brain and a comparison to activity at $\mathrm{pH}$ 5.0. J. Lipid Res. 17:506-515.

Rhoads, R. P., J. W. Kim, B. J. Leury, L. H. Baumgard, N. Segoale, S. J. Frank, D. E. Bauman, and Y. R. Boisclair. 2004. Insulin increases the abundance of the growth hormone receptor in liver and adipose tissue of periparturient dairy cows. J. Nutr. 134:1020-1027.

Rico, D. E., J. A. Parales, B. A. Corl, A. Lengi, P. Y. Chouinard, and R. Gervais. 2015b. Effect of abomasal infusions of saturated fatty acids differing in chain length on milk production, composition, and fatty acid profile in Holstein dairy cows. J. Anim. Sci. 93(Suppl. S3):820.

Rico, J. E., V. V. Bandaru, J. M. Dorskind, N. J. Haughey, and J. W. McFadden. 2015a. Plasma ceramides are elevated in overweight Holstein dairy cows experiencing greater lipolysis and insulin resistance during the transition from late pregnancy to early lactation. J. Dairy Sci. 98:7757-7770.

Rico, J. E., S. L. Giesy, N. J. Haughey, Y. R. Boisclair, and J. W. McFadden. 2018c. Intravenous triacylglycerol infusion promotes ceramide accumulation and hepatic steatosis in dairy cows. J. Nutr. 148:1529-1535.

Rico, J. E., A. T. Mathews, J. Lovett, N. J. Haughey, and J. W. McFadden. 2016. Palmitic acid feeding increases ceramide supply in association with increased milk yield, circulating nonesterified fatty acids, and adipose tissue responsiveness to a glucose challenge. J. Dairy Sci. 99:8817-8830.

Rico, J. E., W. A. Myers, D. J. Laub, A. N. Davis, Q. Zeng, and J. W. McFadden. 2018a. Hot topic: Ceramide inhibits insulin sensitivity in primary bovine adipocytes. J. Dairy Sci. 101:3428-3432.

Rico, J. E., D. E. Rico, Z. C. Phipps, Q. Zeng, B. A. Corl, P. Y. Chouinard, R. Gervais, and J. W. McFadden. 2017a. Circulating ceramide concentrations are influenced by saturated fatty acid chain length in mid-lactation dairy cows. J. Dairy Sci. 2(E-Suppl. 2):394. (Abstr.)

Rico, J. E., S. Saed Samii, A. T. Mathews, J. Lovett, N. J. Haughey, and J. W. McFadden. 2017b. Temporal changes in sphingolipids and systemic insulin sensitivity during the transition from gestation to lactation. PLoS One 12:e0176787.

Rico, J. E., Y. Zang, N. J. Haughey, A. G. Rius, and J. W. McFadden. 2018b. Circulating fatty acylcarnitines are elevated in overweight periparturient dairy cows in association with sphingolipid biomarkers of insulin resistance. J. Dairy Sci. 101:812-819.

Rizza, R. A., L. J. Mandarino, and J. E. Gerich. 1982. Effects of growth hormone on insulin action in man: Mechanisms of insulin resistance, impaired suppression of glucose production, and impaired stimulation of glucose utilization. Diabetes 31:663-669.

Roche, J. R., N. C. Friggens, J. K. Kay, M. W. Fisher, K. J. Stafford, and D. P. Berry. 2009. Invited review: Body condition score and its association with dairy cow productivity, health, and welfare. J. Dairy Sci. 92:5769-5801.

Rozenova, K. A., G. M. Deevska, A. A. Karakashian, and M. N. Nikolova-Karakashian. 2010. Studies on the role of acid sphingomyelinase and ceramide in the regulation of TACE activity and TNF $\alpha$ secretion in macrophages. J. Biol. Chem. 285:21103-21113.

Rukkwamsuk, T., M. Geelen, T. Kruip, and T. Wensing. 2000. Interrelation of fatty acid composition in adipose tissue, serum, and liver of dairy cows during the development of fatty liver postpartum. J. Dairy Sci. 83:52-59.

Schilling, J. D., H. M. Machkovech, L. He, R. Sidhu, H. Fujiwara, K. Weber, D. S. Ory, and J. E. Schaffer. 2013. Palmitate and lipopolysaccharide trigger synergistic ceramide production in primary macrophages. J. Biol. Chem. 288:2923-2932.

Schissel, S. L., G. A. Keesler, E. H. Schuchman, K. J. Williams, and I. Tabas. 1998. The cellular trafficking and zinc dependence of secretory and lysosomal sphingomyelinase, two products of the acid sphingomyelinase gene. J. Biol. Chem. 273:18250-18259.

Schissel, S. L., J. Tweedie-Hardman, J. H. Rapp, G. Graham, K. J. Williams, and I. Tabas. 1996. Rabbit aorta and human atherosclerotic lesions hydrolyze the sphingomyelin of retained low-density lipoprotein. Proposed role for arterial-wall sphingomyelinase in subendothelial retention and aggregation of atherogenic lipoproteins. J. Clin. Invest. 98:1455-1464.

Schoenberg, K. M., S. L. Giesy, K. J. Harvatine, M. R. Waldron, C. Cheng, A. Kharitonenkov, and Y. R. Boisclair. 2011. Plasma FGF21 is elevated by the intense lipid mobilization of lactation. Endocrinology 152:4652-4661.

Schubert, K. M., M. P. Scheid, and V. Duronio. 2000. Ceramide inhibits protein kinase B/Akt by promoting dephosphorylation of serine 473. J. Biol. Chem. 275:13330-13335.

Schwertfeger, K. L., S. M. Anderson, and M. M. Richert. 2001. Mammary gland involution is delayed by activated Akt in transgenic mice. Mol. Endocrinol. 15:867-881.

Sechen, S. J., F. R. Dunshea, and D. E. Bauman. 1990. Somatotropin in lactating cows: Effect on response to epinephrine and insulin. Am. J. Physiol. 258:E582-E588.

Senn, J. J. 2006. Toll-like receptor-2 is essential for the development of palmitate-induced insulin resistance in myotubes. J. Biol. Chem. 281:26865-26875.

Shah, C., G. Yang, I. Lee, J. Bielawski, Y. A. Hannun, and F. Samad. 2008. Protection from high fat diet-induced increase in ceramide in mice lacking plasminogen activator inhibitor 1. J. Biol. Chem. 283:13538-13548.

Sharma, B. K., and R. Erdman. 1989. In vitro degradation of choline from selected foodstuffs and choline supplements. J. Dairy Sci. $72: 2772-2776$.

Shi, H., M. V. Kokoeva, K. Inouye, I. Tzameli, H. Yin, and J. S. Flier. 2006. TLR4 links innate immunity and fatty acid-induced insulin resistance. J. Clin. Invest. 116:3015-3025.

Shimabukuro, M., M. Higa, Y.-T. Zhou, M.-Y. Wang, C. B. Newgard, and R. H. Unger. 1998a. Lipoapoptosis in beta-cells of obese prediabetic fa/fa rats. Role of serine palmitoyltransferase overexpression. J. Biol. Chem. 273:32487-32490.

Shimabukuro, M., Y.-T. Zhou, M. Levi, and R. H. Unger. 1998b. Fatty acid-induced $\beta$ cell apoptosis: A link between obesity and diabetes. Proc. Natl. Acad. Sci. USA 95:2498-2502.

Smith, E. R., and A. H. Merrill. 1995. Differential roles of de novo sphingolipid biosynthesis and turnover in the" burst" of free sphingosine and sphinganine, and their 1-phosphates and N-acyl-derivatives, that occurs upon changing the medium of cells in culture. J. Biol. Chem. 270:18749-18758.

Sordillo, L. M., and W. Raphael. 2013. Significance of metabolic stress, lipid mobilization, and inflammation on transition cow disorders. Vet. Clin. North Am. Food Anim. Pract. 29:267-278.

Staiger, H., O. Tschritter, C. Kausch, R. Lammers, M. Stumvoll, and H.-U. Häring. 2002. Human serum adiponectin levels are not under short-term negative control by free fatty acids in vivo. Horm. Metab. Res. 34:601-603.

Steinberg, G. R., and B. E. Kemp. 2007. Adiponectin: Starving for attention. Cell Metab. 6:3-4. 
Summers, S. A. 2006. Ceramides in insulin resistance and lipotoxicity. Prog. Lipid Res. 45:42-72.

Summers, S. A., L. A. Garza, H. Zhou, and M. J. Birnbaum. 1998. Regulation of insulin-stimulated glucose transporter GLUT4 translocation and Akt kinase activity by ceramide. Mol. Cell. Biol. 18:5457-5464.

Summers, S. A., and B. H. Goodpaster. 2016. CrossTalk proposal: Intramyocellular ceramide accumulation does modulate insulin resistance. J. Physiol. 594:3167-3170.

Tettamanti, G., R. Bassi, P. Viani, and L. Riboni. 2003. Salvage pathways in glycosphingolipid metabolism. Biochimie 85:423-437.

Thirone, A. C., C. R. Carvalho, S. L. Brenelli, L. A. Velloso, and M. J. Saad. 1997. Effect of chronic growth hormone treatment on insulin signal transduction in rat tissues. Mol. Cell. Endocrinol. 130:33-42.

Thudichum, J. L. W. 1884. A Treatise on the Chemical Constitution of the Brain. Baillière \& Company.

Tippetts, T. S., W. L. Holland, and S. A. Summers. 2018. The ceramide ratio: A predictor of cardiometabolic risk. J. Lipid Res. 59:1549-1550.

Tonks, K. T., A. C. Coster, M. J. Christopher, R. Chaudhuri, A. Xu, J. Gagnon-Bartsch, D. J. Chisholm, D. E. James, P. J. Meikle, and J. R. Greenfield. 2016. Skeletal muscle and plasma lipidomic signatures of insulin resistance and overweight/obesity in humans. Obesity (Silver Spring) 24:908-916.

Trajkovic, K., C. Hsu, S. Chiantia, L. Rajendran, D. Wenzel, F. Wieland, P. Schwille, B. Brügger, and M. Simons. 2008. Ceramide triggers budding of exosome vesicles into multivesicular endosomes. Science 319:1244-1247.

Tucker, H. A. 1981. Physiological control of mammary growth, lactogenesis, and lactation. J. Dairy Sci. 64:1403-1421.

Turpin, S. M., H. T. Nicholls, D. M. Willmes, A. Mourier, S. Brodesser, C. M. Wunderlich, J. Mauer, E. Xu, P. Hammerschmidt, H. S. Brönneke, and A. Trifunovic. 2014. Obesity-induced CerS6-dependent C16:0 ceramide production promotes weight gain and glucose intolerance. Cell Metab. 20:678-686.

Turpin-Nolan, S. M., P. Hammerschmidt, W. Chen, A. Jais, K. Timper, M. Awazawa, S. Brodesser, and J. C. Brüning. 2019. CerS1derived C18: 0 ceramide in skeletal muscle promotes obesity-induced insulin resistance. Cell Rep. 26:1-10.e7.

Unger, R. H. 2002. Lipotoxic diseases. Annu. Rev. Med. 53:319-336.

Vernon, R. G., A. Faulkner, W. Hay, D. Calvert, and D. Flint. 1990. Insulin resistance of hind-limb tissues in vivo in lactating sheep. Biochem. J. 270:783-786.

Vernon, R. G., and E. Taylor. 1988. Insulin, dexamethasone and their interactions in the control of glucose metabolism in adipose tissue from lactating and nonlactating sheep. Biochem. J. 256:509-514.

Vesper, H., E.-M. Schmelz, M. N. Nikolova-Karakashian, D. L. Dillehay, D. V. Lynch, and A. H. Merrill Jr.. 1999. Sphingolipids in food and the emerging importance of sphingolipids to nutrition. J. Nutr. 129:1239-1250.
Wang, J., D. Bu, J. Wang, X. Huo, T. Guo, H. Wei, L. Zhou, R. Rastani, L. Baumgard, and F. D. Li. 2010. Effect of saturated fatty acid supplementation on production and metabolism indices in heat-stressed mid-lactation dairy cows. J. Dairy Sci. 93:4121-4127.

Wang, Z., X. Hou, B. Qu, J. Wang, X. Gao, and Q. Li. 2014. Pten regulates development and lactation in the mammary glands of dairy cows. PLoS One 9:e102118.

Watt, M. J., A. Barnett, C. Bruce, S. Schenk, J. Horowitz, and A. Hoy. 2012. Regulation of plasma ceramide levels with fatty acid oversupply: Evidence that the liver detects and secretes de novo synthesised ceramide. Diabetologia 55:2741-2746.

Wiesner, P., K. Leidl, A. Boettcher, G. Schmitz, and G. Liebisch. 2009. Lipid profiling of FPLC-separated lipoprotein fractions by electrospray ionization tandem mass spectrometry. J. Lipid Res. 50:574-585.

Wilson, L. A., S. E. Mills, E. Finley, E. Kilgour, P. J. Buttery, and R. G. Vernon. 1996. Effect of lactation on insulin signal transduction in sheep adipose tissue and skeletal muscle. J. Endocrinol. $151: 469-480$

Wong, M.-L., B. Xie, N. Beatini, P. Phu, S. Marathe, A. Johns, P. W. Gold, E. Hirsch, K. J. Williams, and J. Licinio. 2000. Acute systemic inflammation up-regulates secretory sphingomyelinase in vivo: A possible link between inflammatory cytokines and atherogenesis. Proc. Natl. Acad. Sci. USA 97:8681-8686.

Worgall, T. S. 2007. Sphingolipids: Major regulators of lipid metabolism. Curr. Opin. Clin. Nutr. Metab. Care 10:149-155.

Yang, G., L. Badeanlou, J. Bielawski, A. J. Roberts, Y. A. Hannun, and F. Samad. 2009. Central role of ceramide biosynthesis in body weight regulation, energy metabolism, and the metabolic syndrome. Am. J. Physiol. Endocrinol. Metab. 297:E211-E224.

Yonezawa, T., S. Haga, Y. Kobayashi, K. Katoh, and Y. Obara. 2008 Unsaturated fatty acids promote proliferation via ERK1/2 and Akt pathway in bovine mammary epithelial cells. Biochem. Biophys. Res. Commun. 367:729-735.

Yoon, Y. J., O. Y. Kim, and Y. S. Gho. 2014. Extracellular vesicles as emerging intercellular communicasomes. BMB Rep. 47:531

Zachut, M., H. Honig, S. Striem, Y. Zick, S. Boura-Halfon, and U. Moallem. 2013. Periparturient dairy cows do not exhibit hepatic insulin resistance, yet adipose-specific insulin resistance occurs in cows prone to high weight loss. J. Dairy Sci. 96:5656-5669.

Zeidan, Y. H., and Y. A. Hannun. 2007. Translational aspects of sphingolipid metabolism. Trends Mol. Med. 13:327-336.

Zeisel, S. H., D. Char, and N. F. Sheard. 1986. Choline, phosphatidylcholine and sphingomyelin in human and bovine milk and infant formulas. J. Nutr. 116:50-58.

Zhang, T., J. Huang, Y. Yi, X. Zhang, J. J. Loor, Y. Cao, H. Shi, and J. Luo. 2018. Akt serine/threonine kinase 1 regulates de novo fatty acid synthesis through the mammalian target of rapamycin/sterol regulatory element binding protein 1 axis in dairy goat mammary epithelial cells. J. Agric. Food Chem. 66:1197-1205. 